\title{
Geschichte des Novatianismus seit dem vierten Jahrhundert im Osten
}

\author{
von Martin Wallraff
}

Der Streit zwischen Cornelius und Novatian und das daraus resultierende Schisma gehören zu den loci classici der Kirchengeschichte des dritten Jahrhunderts. Das ist insofern berechtigt, als sich am Kern der Kontroverse, der Frage, wie die Kirche mit den in der Verfolgung Abgefallenen umzugehen habe, wichtige Paradigmen des Lebens der Kirche jener Zeit aufzeigen lassen. Neben persönlichen Motiven und Intrigen zeichnen sich die Grundzüge der kirchlichen Bußlehre ab. Aus diesem Grunde hat die Forschung der Entstehung des Novatianismus einiges Interesse entgegengebracht ${ }^{1}$. Der Streit war jedoch mit dem Tod der beiden Hauptprotagonisten keineswegs endgültig überwunden. Vielmehr hielt sich die von Novatian gegründete Sondergemeinschaft mehrere Jahrhunderte lang und fand Verbreitung weit über Rom hinaus. Für diese Phase der Entwicklung ist vergleichsweise sehr wenig Forschungsarbeit geleistet worden - wofür sich verschiedene Gründe finden lassen. Die Hauptursache liegt zweifellos darin, daß sich im Novatianismus nach Novatian wenig neue theologische Motive zeigen, daß also eine Untersuchung dieser Phase verhältnismäßig geringen dogmengeschichtlichen Erkenntnisgewinn verspricht. Dieser Sachverhalt rechtfertigt jedoch nicht, das Thema ganz links liegen $\mathrm{zu}$ lassen, denn die erhaltenen Zeugnisse zeigen, daß die novatianische $\mathrm{Ge}-$ meinde in sozialer und (kirchen-)politischer Hinsicht von einiger Bedeutung war, so daß eine Untersuchung einen wichtigen Beitrag zum Verständnis der Kirchengeschichte des vierten und fünften Jahrhunderts leisten kann. Davon abgesehen ist das Thema auch in theologischer Hinsicht nicht so uninteressant, wie es auf den ersten Blick scheinen mag. Denn der Anlaß der Spaltung, das Problem der Wiederaufnahme der lapsi, war mit

1 Neben den einschlägigen Kapiteln in Lehrbüchern und Überblicksdarstellungen (zuletzt K.S. Frank, Lehrbuch der Geschichte der Alten Kirche, Paderborn 1996, 167-170) vgl. A. Harnack, Art. Novatian, Novatianisches Schisma, Katharische Kirche, RE 14, Leipzig 31904, (223-242) 223-240; É. Amann, Art. Novatien et Novatianisme, DThC 11,1, Paris 1931, (816-849) 816-841; H.J. Vogt, Coetus Sanctorum. Der Kirchenbegriff des Novatian und die Geschichte seiner Sonderkirche, Theoph. 20, Bonn 1968, 17-56; T.E. Gregory, Novatianism. A Rigorist Sect in the Christian Roman Empire, Byzantine Studies/Etudes Byzantines 2, 1975, (1-18) 2-4; H.J. Vogt, Art. Novaziano, DPAC 2, Casale Monferrato 1984, 2436-2439; J.S. Alexander, Art. Novatian/Novatianer, TRE 24, Berlin 1994, (678-682) 678-681 (mit weiterer Lit.). Speziell mit dem Bericht des Sokrates über Novatian (h.e. IV 28) befaßt sich C. Curti, Lo scisma Novaziano nell'interpretazione dello storico Socrate, La storiografia ecclesiastica nella tarda antichità, Messina 1980, 313-333. 
dem Ende der Verfolgungszeit weggefallen. Es stellt sich also die Frage, worin die Gemeinde unter den veränderten Umständen seit dem vierten Jahrhundert ihre Existenzberechtigung sah, und was als entscheidender theologischer Differenzpunkt zur Großkirche galt.

Ein anderer Grund für die unbefriedigende Forschungslage liegt in der Eigenart der Quellenlage: Zumindest im Osten des römischen Reiches stammt der bei weitem überwiegende Teil des zur Verfügung stehenden Materials aus einer einzigen Quellenschrift, der Kirchengeschichte des Sokrates $^{2}$, die auffällig und erstaunlich viel über die Novatianer berichtet. Weitere kleinere Nachrichten sind breit verstreut in unterschiedlichsten Quellengattungen zu finden. Die wenigen Forschungsarbeiten zum Thema beschränken sich meist weitgehend auf eine Wiedergabe des von Sokrates Gebotenen ${ }^{3}$. Doch so naheliegend und einfach ein solches Vorgehen ist, so wenig befriedigt es in methodischer Hinsicht. Die Hauptschwierigkeit liegt dabei darin, daß die Nachrichten des Geschichtsschreibers nicht ohne weiteres übernommen werden sollten, ohne daß seine Haltung zu der Sondergemeinschaft und der Grund für sein Interesse an ihr eingehend geprüft sind. Es genügt nicht, allgemein auf das hohe Maß an Glaubwürdigkeit zu verweisen, das ihm gewöhnlich und in anderen Bereichen zuerkannt zu werden pflegt $^{4}$. Ebensowenig ist es genug, sich auf die communis opinio zu berufen, derzufolge der Kirchenhistoriker selbst nicht Novatianer, sondern orthodox war ${ }^{5}$. Diese Auffassung ist nicht nur schwach begründet, sondern sie würde auch nicht ausschließen, daß der

2 Der Text ist jetzt in einer ausgezeichneten kritischen Edition verfügbar: Sokrates, Kirchengeschichte, hg. von G.C. Hansen, mit Beiträgen von M. Sirinjan, GCS N.F. 1, Berlin 1995.

3 Vgl. Harnack, Novatian (wie Anm. 1), 240-242; Amann, Novatien (wie Anm. 1), 841849; R. Janin, Les Novatiens orientaux, EOr 28, 1929, 385-397; Vogt, Coetus (wie Anm. 1), 236-264; Gregory, Novatianism (wie Anm. 1), 4-16; A. Ferrarini, Eresia e storia ecclesiastica. Contributi novaziani alla storiografia di Socrate (Scolastico), Annali della Facoltà di Lettere e Filosofia di Padova 4, 1979, 127-185; R.J. de Simone, Art. Novaziani, DPAC 2, Casale Monferrato 1984, 2434-2436; Alexander, Novatian (wie Anm. 1), 681. Dagegen ist die mühselige Auswertung der Nebenquellen noch keineswegs abgeschlossen. Die bisher vollständigste Analyse ist die von Vogt, Coetus (wie Anm. 1), 200-211; 240-245; 248-256; 282-290. Eine neue Analyse des Materials bei Sokrates im Lichte der hier vorgelegten Untersuchung habe ich in M. Wallraff, Socrates Scholasticus on the History of Novatianism, StPatr, hg. v. E.A. Livingstone, Löwen 1997 (im Druck) versucht.

4 Vgl. etwa W. Eltester, Art. Sokrates Scholasticus, PRE 3/1 A, Stuttgart 1927, (893-901) 899.

5 Diese Sicht geht auf Henri Valois, den großen Erforscher und Herausgeber der spätantiken Kirchengeschichtswerke im siebzehnten Jahrhundert, zurück. Die nach wie vor wertvolle Einleitung sowie der Kommentar seiner Sokrates-Edition von 1668 sind noch einmal abgedruckt bei: Socratis Scholastici Ecclesiastica Historia, hg. v. R. Hussey, 3 Bde., Oxford 1853 und werden danach zitiert. Dort heißt es: Novatianum illum fuisse, agre admodum mibi persuaserim; prasertim cum ex aliquot locis quae in eius historia occurrunt, contrarium mibi videar deprebendisse (1,xii). Vorangegangen waren, besonders im 16. Jahrhundert, heftige Diskussionen über den Novatianismus des Sokrates. Die Forschung hat seither an Valois' Urteil ohne nähere Untersuchung festgehalten. Eine 
Historiker bei diesem Thema voreingenommen und tendenziös berichtet. Vielmehr ist es nötig, das Bild des Sokrates sorgfältig mit dem Befund der anderen Quellen zu vergleichen, um auf diese Weise erstens ein möglichst zuverlässiges Bild vom Geschick der novatianischen Kirchengemeinschaft zu erhalten und zweitens die Grundlage zu schaffen für ein begründetes Urteil über die Stellung des Sokrates zum Novatianismus.

Ziel des vorliegenden Aufsatzes ist es daher, die Geschichte des Novatianismus im Osten des römischen Reiches von der konstantinischen Zeit bis zu ihrem Aussterben in erster Linie auf der Basis der von Sokrates unabhängigen Quellen zu verfolgen. Diese Quellen zerfallen in drei Gruppen sehr unterschiedlicher Größe. Bedauerlicherweise am kleinsten ist (I) die Gruppe der direkt aus der novatianischen Kirche überkommenen Zeugnisse. Weiteren Aufschluß erhält man (II) aus rechtlichen Regelungen, die sich mit Häretikern befassen, und zwar sowohl aus dem staatlichen als auch aus dem kirchlichen Bereich. Die mit Abstand größte Gruppe schließlich stellt (III) das von den theologischen Gegnern und Bestreitern (meist orthodoxer Prägung) verfaßte Schrifttum dar. Nach der Analyse dieser Quellengruppen soll (IV) die Haltung der Novatianer zum Ostertermin eigens untersucht werden - ein Themenkomplex, dem, wie sich zeigen wird, besondere Bedeutung zukommt.

I.

Auch wenn die erste Gruppe am kleinsten ist, gibt sie doch sehr wichtige Informationen. Ein eigenständiges novatianisches Schrifttum hat sich nicht erhalten - zumindest wenn man nicht Sokrates, dessen Position ja noch genauer zu untersuchen wäre, dazurechnen möchte. Zwar sind sowohl von dem Konstantinopolitaner Novatianerbischof Sisinnios im Osten als auch von einem sonst nicht weiter bekannten Sympronianus im Westen literarische Aktivitäten bezeugt, doch ist davon fast nichts auf uns gekommen $^{6}$. Ein kurzer hagiographischer Text, die Vita Autonomi (BHG 198), ist jüngst von $\mathrm{C}$. Foss als novatianisch in Anspruch genommen worden,

neue Prüfung der Frage nehme ich in M. Wallraff, Der Kirchenhistoriker Sokrates. Untersuchungen zu Geschichtsdarstellung, Methode und Person, FKDG 68, Göttingen 1997, 235-255 vor, dort auch eine Zusammenstellung der bisherigen Forschungsäußerungen (S. 255 Anm. 116).

6 Fragmente des Schriftums von Sympronianus sind in der gegen ihn gerichteten Schrift von Pacianus von Barcelona erhalten, vgl. Vogt, Coetus (wie Anm. 1), 227-234 sowie die neue Edition: Pacien de Barcelone, Ecrits, hg. v. C. Granado, SC 410, Paris 1995, zum Adressaten Sympronianus bes. 45-48. Literarische Aktivitäten des Sisinnios: Sokrates, h.e. VI 21,6; VI 22,21. Davon ist jedoch nichts erhalten. Der Versuch von P. Battifol, L'auteur véritable de l'epistula ad Zenam et Serenum, RB 5, 1896, 114-122, die pseudojustinische Epistula ad Zenam et Serenum (CPG 1085) als Werk des Sisinnios zu erweisen, hat wenig Anklang gefunden, vgl. Vogt, Coetus (wie Anm. 1), 258 Anm. 79. 
doch bedarf diese Zuweisung noch eingehenderer Diskussion?. Ansonsten bleibt als einzige Primärquelle novatianischer Provenienz das epigraphische Material. Dabei handelt es sich um etwa ein halbes Dutzend eindeutig novatianischer Grabinschriften aus Kleinasien ${ }^{8}$. Was dabei zunächst auffällt, ist die wechselnde Selbstbezeichnung: Als feststehende Formulierung

7 Die von C. Foss, St. Autonomus and His Church in Bithynia, DOP 41, 1987, 187-198 (= ders., History and Archeology of Byzantine Asia Minor, Aldershot 1990, Nr. V) vorgebrachten Argumente beziehen sich im wesentlichen auf die geographischen Angaben über die Fahrten des Autonomos. Da diese Angaben - falls Foss' These richtig sein sollte

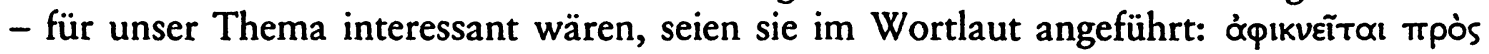

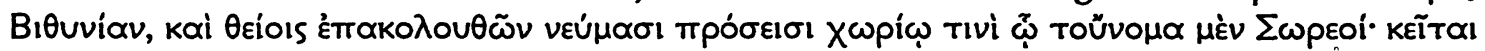

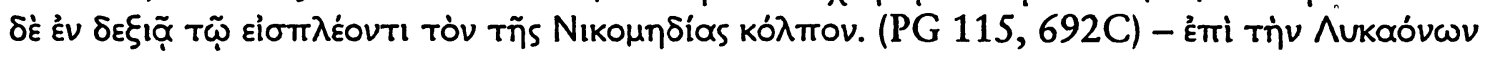

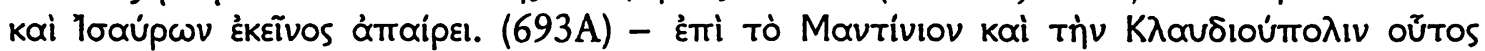

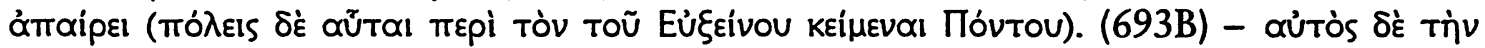

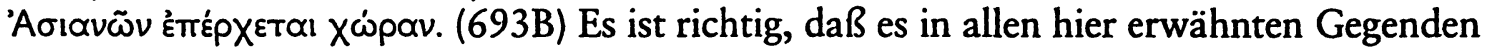
nachweislich Novatianer gab (s. das Folgende), doch es scheint mir fraglich, ob diese Beobachtung allein genügt, um die Vita als novatianisch in Anspruch nehmen zu können. Zumindest an dem für die Vita wichtigsten Ort, nämlich der Gegend um Nikomedien (wo sich die Kirche des Autonomos befunden haben soll), waren die Orthodoxen ebenfalls gut vertreten, ebenso in Lykaonien und Isaurien. Auch werden die von Foss 188-190 beschriebenen Probleme der Vita keineswegs durch seine Hypothese alle gelöst. Wenn der

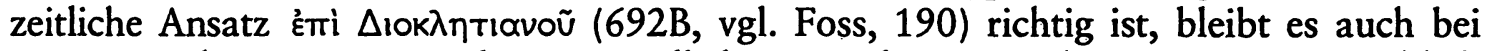
novatianischem Hintergrund unverständlich, wieso die Reisen des Autonomos angeblich Missionsreisen in - kirchlich gesehen - völliges Neuland waren. Denn der achte Kanon des Konzils von Nikaia (s. Anm. 26) zeigt, daß die Verbreitung der Novatianer schon 325 sehr weit fortgeschritten war. Auf jeden Fall aber weist die These von Foss einen interessanten und vielversprechenden Weg, auf dem es sich lohnt weiterzugehen. Denn völlig zu Recht bemerkt Foss, 191f., daß heterodoxe hagiographische Überlieferungen manchmal recht problemlos in die orthodoxe Tradition überwechseln - zumal wenn ihr ursprünglicher „Besitzer“, die Gruppierung, in der sie entstanden sind, ausstirbt. Gutes Beispiel sind die homöischen Märtyrertraditionen aus der Mitte des vierten Jahrhunderts, die H.Ch. Brennecke, Studien zur Geschichte der Homöer. Der Osten bis zum Ende der homöischen Reichskirche, BHTh 73, Tübingen 1988, 114-157 analysiert hat. Im Falle des Autonomos müßte man allerdings annehmen, daß auch eine Lokaltradition (Märtyrergrab) „konvertiert“ worden ist (vgl. Foss, 193-195), was sicherlich viel problematischer ist.

8 In Frage kommen folgende Inschriften, jeweils mit der die Kirchenzugehörigkeit ausdrückenden Formulierung: 1. Monumenta Asiae Minoris Antiquae, 8 Bde., Manchester 1928-62, Bd.1, Nr. 172 = W.M. Calder, The Epigraphy of Anatolian Heresies, in: Anatolian Studies presented to Sir William Mitchell Ramsay, hg. v. W.H. Buckler/W.M.

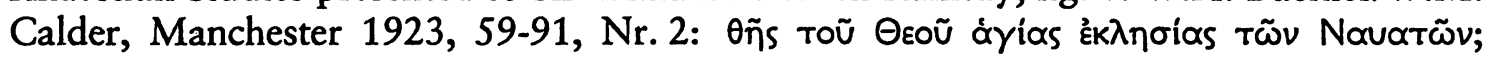

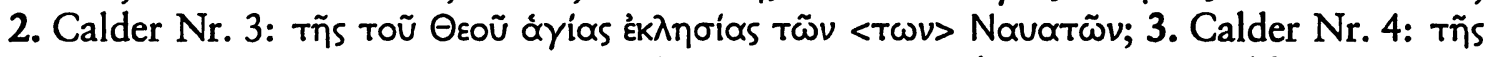

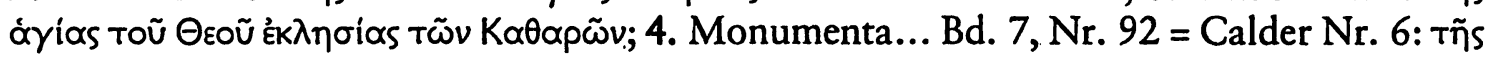

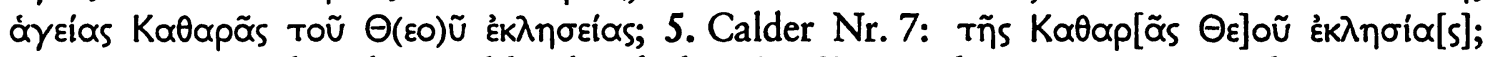
6. C.H.E. Haspels, The Highlands of Phrygia. Sites and Documents, 2 Bde, Princeton

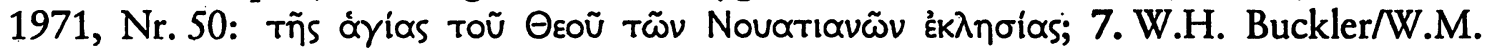
Calder/C.W.M. Cox, Asia Minor, 1924. IV. - A Monument from the Upper Tembris

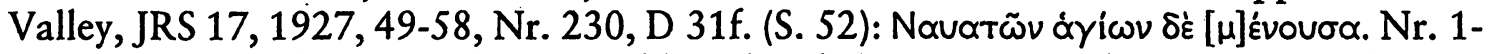
5 stammen aus der Gegend um Laodikeia katakekaumene (Pisidien), Nr. 6 und 7 aus Ostphrygien (Phrygia salutaris). Zum folgenden vgl. auch S. Mitchell, Anatolia. Land, Men, and Gods in Asia Minor, Bd. 2, The Rise of the Church, Oxford 1993, 100-108 (und die Landkarte S. 94). 
werden die Bestatteten als Mitglieder „der heiligen Kirche Gottes“ be-

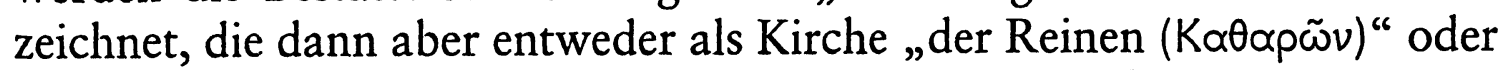

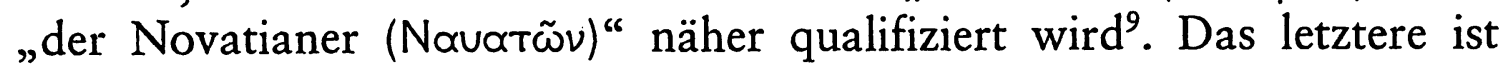
besonders deshalb bemerkenswert, weil die Bezeichnung bestimmter Kirchenparteien nach der Person ihres Gründers bzw. Lehrers in der Regel nur als Fremdbezeichnung auftritt (keine Kirche hat sich je arianisch, eunomianisch, makedonianisch usw. genannt). Möglicherweise hat sich auch bei den Novatianern diese Benennung erst allmählich, in der dritten oder vierten Generation, als Selbstbezeichnung durchgesetzt ${ }^{10}$. Weiterhin fällt auf, daß der größte Teil der hier in Frage kommenden Inschriften von Klerikergräbern stammt ${ }^{11}$. Da ja die Novatianer keine reine Klerikergemeinde gewesen sein werden, ist die Vermutung naheliegend, daß auch von den vielen christlichen Grabinschriften ohne besondere novatianische Charakteristika ein gut Teil dieser Gemeinde angehört hat (die Kleriker neigten eben besonders dazu, ihr Bekenntnis herauszustellen $)^{12}$. Dieser Schluß erfährt eine gewisse Unterstützung durch die Tatsache, daß sich aus derselben Gegend die Grabinschrift eines Presbyters erhalten hat, dessen Angehörige es für nötig hielten, eigens zu betonen, daß er „der heiligen Kirche der Orthodoxen " angehörte ${ }^{13}$. Auch die längste und aufschlußreichste der novatianischen Inschriften, die für den Presbyter Eugenios, zeigt, daß die „Reinen“ in dieser Gegend keine marginale Erscheinung waren: Eugenios wird gerühmt, reich und edel gewesen zu sein und „bedeutend vor allen im Dorf“. Sein Ruhm umfasse alle Himmelsrichtungen - eine rhetorische Übertreibung, die glücklicherweise näher präzisiert

9 Novatianer: Nr. 1, 2, 6, 7 der vorigen Anm.; Katharer: Nr. 3, 4, 5.

10 Die fraglichen Inschriften stammen aus dem späten vierten Jahrhundert (Calder, Epigraphy [wie Anm. 8], 74), nur Nr. 7 aus der ersten Hälfte des Jahrhunderts (Buckler, Asia [wie Anm. 8], 55). Als Fremdbezeichnung ist der Name "Novatianer" von Anfang an geläufig. Eine gewisse Analogie kann man übrigens in der Benennung „Lutheraner“ sehen, die erst im 19. Jahrhundert als Selbstbezeichnung übernommen wurde.

Von den in Anm. 8 genannten Inschriften stammen zwei vom Grab eines Presbyters (Nr. 1, 3) und je eine vom Grab eines Diakons (Nr. 2) bzw. Anagnosten (Nr. 6). G. Laminger-Pascher, Beiträge zu den griechischen Inschrifen Lykaoniens, Ergänzungsbände zu den Tituli Asiae Minoris 11, Wien 1984, 70-72, versucht mit viel Scharfsinn, die Inschrift Nr. 4 so zu ergänzen, daß deutlich wird, um was für einen Amtsträger es sich bei dem bestatteten Novatianer handelte. Doch dürfte sich mit Sicherheit nur sagen lassen, daß die früher vertretene Lesart ìyoúpevos nicht zu halten ist.

Dennoch ist es schwierig, konkrete Zuweisungen vorzunehmen. Die Formulierung í ó $\gamma$ ía

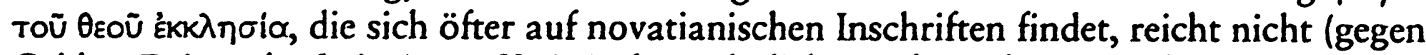
Calder, Epigraphy [wie Anm. 8], 81), denn ähnlich wurde auch von Orthodoxen formuliert (s. nächste Anm.). Immer wieder wird auf Inschriften rühmend hervorgehoben, daß der oder (meist) die Verstorbene nur einmal verheiratet war (vgl. Mitchell, Anatolia [wie Anm. 8], 107), doch ist die Betonung dieser Frage nicht zwingend ein Charakteristikum novatianischer Theologie, vgl. z.B. die Stellung des Basileios (s. unten S. 260-262).

13

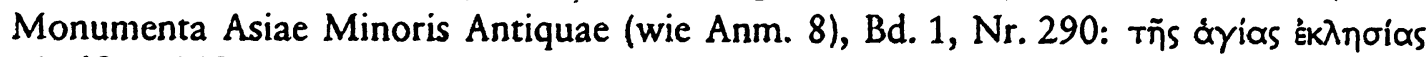

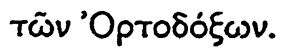


wird: Phrygien, Asien und Anatolien ${ }^{14}$. Auch wenn es aufgrund der wenigen Inschriften nicht möglich ist, genauere Angaben über die Verbreitung zu machen, ist es doch klar, daß zumindest in Phrygien und Pisidien die Novatianer eine bedeutende Rolle gespielt haben. Sicherlich gab es einzelne Ortschaften, womöglich auch geschlossene Landstriche, in denen sie die Majorität darstellten ${ }^{15}$. Dieser Befund bestätigt die Angaben des Sokrates $^{16}$.

Aus der Eugenios-Inschrift läßt sich noch mehr erkennen: Nicht nur gehörte der Novatianerpresbyter offensichtlich der finanziellen und sozialen Elite der Ortschaft an, sondern seine Angehörigen hatten auch keine Bedenken, auf dem Grab gehörig darauf hinzuweisen. Zumindest an dieser Stelle scheint ein theologisches Armutsideal, das man bei einer rigoristischen Sekte vermuten könnte, keine Rolle gespielt zu haben (sehr wohl wird allerdings die Wohltätigkeit des Verstorbenen betont). Weitere Aussagen über die Theologie der Novatianer lassen sich aus dieser Inschrift leider kaum gewinnen, obgleich sie einen christologischen Passus enthält, der der Interpretation jedoch große Schwierigkeiten bereitet. Sicher kann nur gesagt werden, daß dort die Rede ist von einem „ersten Engel“, wohl auf Christus bezogen ${ }^{17}$. Auch die anderen novatianischen Inschriften lassen wenig über das theologische Profil dieser Gruppierung erkennen.

\section{II.}

Während sich in diesen epigraphischen Zeugnissen eher die Verhältnisse in der Provinz spiegeln, zeigt die zweite Quellengruppe, die rechtlichen Regelungen über Häretiker, speziell die Novatianer, daß dort auch die haupt-

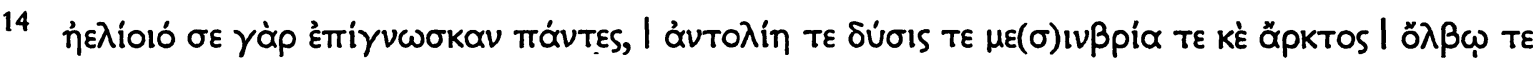

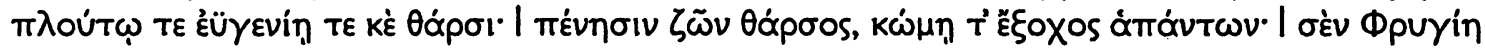

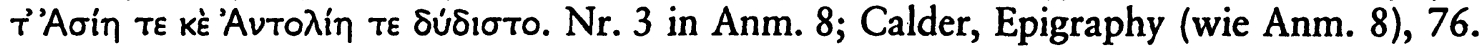
Die beste Abbildung dieses wichtigen Grabsteins bei Mitchell, Anatolia (wie Anm. 8), 101, fig. 24.

15 So auch Vogt, Coetus (wie Anm. 1), 279; Mitchell, Anatolia (wie Anm. 8), 104. Vgl. ferner das sich aus dem achten nizänischen Kanon ergebende Bild (unten S. 258).

Das gilt auf jeden Fall für Phrygien, vgl. Sokrates, h.e. IV 28,1.8-16.

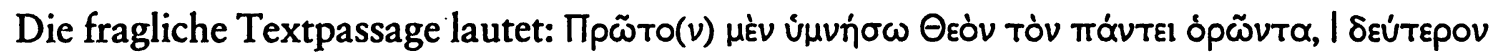

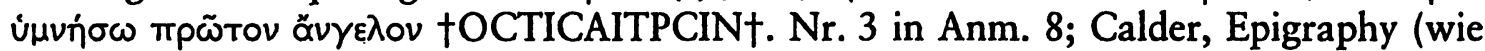
Anm. 8), 76. Die letzten Buchstaben bleiben rätselhaft. Die geistreiche Interpretation von H. Grégoire, Un nom mystique du Christ dans une inscription de Pisidie, Byz. 2, 1925, 449-453, hat Zustimmung (A. Wilhelm, Griechische Grabinschriften aus Kleinasien, SPAW.PH, 1932, [792-865] 829-831; F. Scheidweiler, Novatian und die Engelchristologie, ZKG 66, 1954/55, [126-139] 136; Mitchell, Anatolia [wie Anm. 8], 102 Anm. 406), aber auch (m.E. berechtigte) Ablehnung gefunden (Vogt, Coetus [wie Anm. 1], 280). Auch wenn die Bezeichnung Christi als erster Engel nicht daran hängt, ist diese eine Inschrift keine hinreichende Basis, um daraus eine novatianische Engelchristologie abzuleiten (so Scheidweiler), zumal die übrigen von Scheidweiler beigebrachten Argumente nicht überzeugen, vgl. Vogt, Coetus, 281. 
städtischen Verhältnisse im Blick sind. Zunächst zur staatlichen Gesetzgebung: Schon unter Konstantin erhielten die Novatianer innerhalb der Häretikergesetzgebung eine auffällige Sonderstellung. In einem Gesetz vom 1. September 326 und einem vermutlich um etwa die gleiche Zeit verfaßten Brief des Kaisers wurden alle Häretiker aufs strengste verurteilt und sämtlicher Privilegien beraubt ${ }^{18}$. Doch keine vier Wochen später erließ die kaiserliche Kanzlei ein Gesetz, durch das speziell die Novatianer von dieser Regelung ausgenommen wurden: Sie durften ihre Kirchen und Begräbnisstätten behalten ${ }^{19}$. Diese Privilegierung kam aufgrund einer novatianischen Petition zustande ${ }^{20}$. Es liegt auf der Hand, daß es sich dabei kaum um irgendwelche phrygische Bauern gehandelt haben wird. Schon vor der Etablierung der Führungselite in der neuen Hauptstadt Konstantinopel hat es also novatianische Interessenvertreter gegeben, deren Einfluß bei Hofe weit genug reichte, um die partielle Rücknahme eines einmal erlassenen Gesetzes zu erwirken.

Auch in der Folgezeit gelang es den Novatianern, ihre privilegierte Stellung zu behaupten. Daß sie im Häretikergesetz Theodosios' I. nicht auftauchen, ist sicherlich ein vielsagendes Schweigen und bestätigt die auch von Sokrates bezeugte wohlwollende Haltung dieses Kaisers zu der Sonderkirche ${ }^{21}$. Unter Theodosios II. werden sie zwar einmal in einem Häretikergesetz erwähnt (übrigens zusammen mit den Sabbatianern, der schismatischen Gruppe, die sich inzwischen gebildet hatte) ${ }^{22}$, doch in einem später erlassenen, differenzierteren Gesetz wird ihre Sonderstellung

Das Gesetz: C.Th. XVI 5,1 vom 1. September 326; der Brief: Euseb, v.C. III 64f. Vogt, Coetus (wie Anm. 1), 194-196, sieht unnötigerweise einen Widerspruch zwischen diesem Brief und dem in der folgenden Anm. zitierten Gesetz: Es spricht ja nichts dagegen, daß der Brief vor dem Gesetz abgefaßt ist - gewiß nicht die Tatsache, daß das Gesetz keinen Bezug auf den Brief nimmt (Vogt 195); das wäre bei der knappen Form der Gesetzestexte keinesfalls zu erwarten (so auch $H$. Dörries, Das Selbstzeugnis Kaiser Konstantins, AAWG.PH 3,34, Göttingen 1954, 84; K.-L. Noethlichs, Die gesetzgeberischen Maßnahmen der christlichen Kaiser des vierten Jahrhunderts gegen Häretiker, Heiden und Juden, Diss.phil. [masch.] Köln 1971, 12, setzt den Brief in der Zeit zwischen den Gesetzen C.Th. XVI 5,1 und XVI 5,2 an).

19 C.Th. XVI 5,2 (855,2f. Mommsen/Meyer) vom 25. September 326; das Gesetz bezeichnet die Novatianer sogar als eine ecclesia. Vgl. auch Sozomenos, h.e. II 32,5 (von Sokrates unabhängig!).

20 Das Gesetz spricht von dem, quae petiverunt (855,1f. Mommsen/Meyer). Vgl. Noethlichs, Maßnahmen (wie Anm. 18), 14 mit Recht: „Eine rein religiöse Begründung für [C.Th.] XVI 5,2 gibt es m. E. nicht.“

21 C.Th. XVI 5,6 vom 10. Januar 381, vgl. Vogt, Coetus (wie Anm. 1), 244 und Noethlichs, Maßnahmen (wie Anm. 18), 133f. Die umständliche Festlegung auf den nizänischen Glauben (857,2-9 Mommsen/Meyer) könnte geradezu darauf abzielen, die Novatianer mit einzuschließen, vgl. Sokrates, h.e. V 10,26f. Die Angabe des Sokrates, h.e. V 10,28 und V 20,6, Theodosios I. habe sogar ein eigenes Schutzgesetz für die Novatianer erlassen, bestätigt sich in den uns erhaltenen Gesetzestexten jedoch nicht. Andere „Ketzerkataloge", in denen die Novatianer fehlen: C.Th. XVI 5,8.9.11.12.13.

22 C.Th. XVI 5,59 (876,3 Mommsen/Meyer) vom 9. April 423; zum sabbatianischen Schisma s. unten S. 273-277. 
gegenüber den anderen Häresien bekräftigt. Lediglich Neuerwerbungen an Kirchen sind ihnen untersagt ${ }^{23}$. Diese Sonderbehandlung läßt sich nur durch das Vorhandensein einer bei Hofe einflußreichen Gruppe in der Hauptstadt erklären, deren Existenz übrigens auch von Sokrates bezeugt wird (h.e. IV 9,4-6).

In einem weiteren Text ergreift der Gesetzgeber Partei in dem innernovatianischen Streit um das Osterfest: Schwere Strafen werden den "Protopaschiten“ angedroht, also denjenigen, die vor dem Termin der Großkirche feiern ${ }^{24}$. Auf diesen Text ist im Zusammenhang der von Sokrates gelieferten Informationen über den Streit noch zurückzukommen.

Auch kirchliche Rechtsentscheidungen des vierten Jahrhunderts befassen sich immer wieder mit den Novatianern und lassen auf diese Weise erkennen, daß das Problem virulent war. Meist geht es dabei um die konkrete Fragestellung, was mit denjenigen zu geschehen hat, die von der novatianischen zur orthodoxen Kirche übertreten. Der achte Kanon von Nikaia hat im wesentlichen die übertretenden Kleriker im Blick: Sie behalten in der Regel ihren Rang, müssen dazu aber neu ordiniert werden ${ }^{25}$. Bei Bischöfen muß allerdings darauf geachtet werden, daß es nicht auf einmal zwei am gleichen Ort gibt. Diese entgegenkommende Regelung soll sicherConstantin dem Großen zu Theodosius II. Das christliche Kaisertum bei den Kirchenhistorikern Socrates, Sozomenus und Theodoret, Hyp. 110, Göttingen 1996, 269 Anm. 121, rechnet damit, daß diese Gesetze in der Praxis nicht streng durchgesetzt wurden.

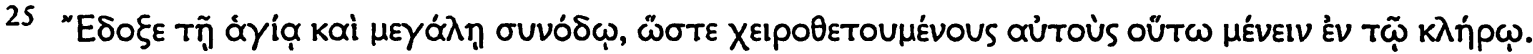
(C Nic. [325], can. 8 [1,30,4-9 Joannou]). Die Deutung dieser Passage ist problematisch.

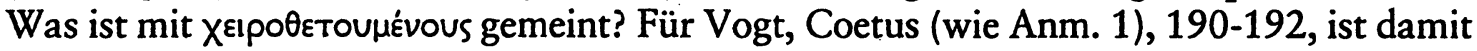
eine Handauflegung "als Rekonziliationsritus“ (192) gemeint, also keine Ordination.

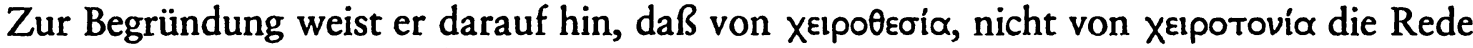
ist. Das ist in der Tat auffällig, doch bei näherem Hinsehen zeigt sich, daß aus dieser terminologischen Beobachtung nicht allzu viel zu gewinnen ist. Die von Vogt herangezogenen Vergleichsstellen zeigen nicht den Gebrauch von $\chi \varepsilon i p \circ \theta \varepsilon \sigma i \alpha$ als terminus technicus für rekonziliatorische Handauflegung, sondern nur, daß $\chi$ вıротоvi $\alpha$ der üblichere Begriff für Ordination ist (z.B. weiter unten im gleichen Kanon, 1,30,21f. Joannou). Es

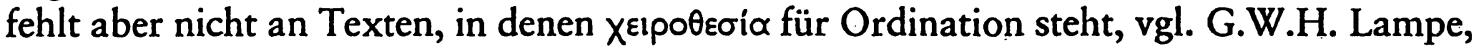
A Patristic Greek Lexicon, Oxford 1961, s.v. sowie L. Mortari, Consacrazione episcopale e collegialità. La testimonianza della Chiesa antica, Florenz 1969, 37f., beim Konzil von Nikaia insbesondere Kanon 19 (1, 41,5 Joannou). Andererseits stellen sich inhaltlich Vogts Interpretation entscheidende Bedenken entgegen: Der gesamte Kanon spricht eindeutig vom Klerus (wie übrigens auch die vorausgehenden und nachfolgenden). Dieser

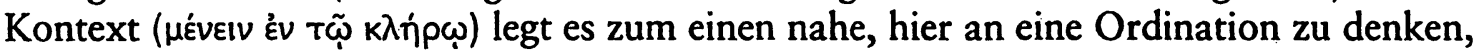
und macht es zum anderen schwer verständlich, warum eine solche rekonziliatorische Handauflegung nur bei konvertierenden Klerikern nötig gewesen sein sollte (und nicht bei allen Gemeindegliedern). Doch auch wenn hier von Ordination die Rede ist, sind damit noch nicht alle Probleme gelöst. Denn man könnte erwägen zu übersetzen: Die Synode beschließt, „daß sie, sofern sie ordiniert sind, in diesem klerischen Rang verbleiben“. Gegen diese Deutung sprechen jedoch m.E. sprachliche Gründe. Das đữoús neben

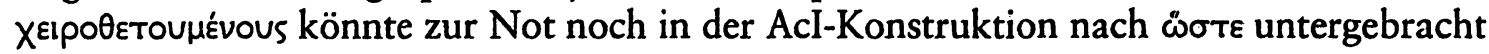


lich den Übertritt möglichst schmackhaft machen. Solches Entgegenkommen hatte die orthodoxe Kirche nötig, weil es geschlossen novatianische Gebiete gab, in denen die Orthodoxie überhaupt erst Fuß zu fassen beabsichtigte ${ }^{26}$. Als Bedingung zum Übertritt wurde natürlich der Verzicht auf die novatianische Lehre gefordert, das heißt Anerkennung der Wiederaufnahme der lapsi und - hier erstmals erwähnt - der zum zweiten Mal Verheirateten ${ }^{27}$. Während das Problem der lapsi mit dem Ende der Verfolgungen zu einem mehr oder minder theoretischen wurde, scheint die Frage der zweimal Verheirateten immer mehr zu einem echten Differenzpunkt in der Praxis geworden zu sein. Die Novatianer hielten an der scharfen Mißbilligung der zweiten (und jeder weiteren) Ehe fest - und damit an einer in der Kirche der ersten drei Jahrhunderte weit verbreiteten Haltung ${ }^{28}$.

Die Frage der Taufanerkennung bei Übertritten, die in Nikaia nicht explizit angesprochen ist ${ }^{29}$, versucht die Synode von Laodikeia Ende des vierten Jahrhunderts zu regeln. Im siebten Kanon wird festgelegt, daß

werden, doch kann dann das Partizip Präsens Passiv kaum in dieser Weise übersetzt werden. Die wahrscheinlichste Lösung scheint mir daher zu sein: Die Synode beschließt, „daß sie, wenn ihnen die Hand [zur Ordination] aufgelegt wird, im Klerus bleiben können“. Diese Lösung hat nicht zuletzt den Vorteil, daß sie verschiedene altkirchliche Leser der nizänischen Beschlüsse auf ihrer Seite hat, etwa Rufin, h.e. X 6 (GCS Eusebius $2 / 2,967,10 f$. Mommsen), der die Stelle übersetzt: ... clericos in ordine quidem suscipi debere, sed ordinatione data. Vgl. ferner Theophil von Alexandrien in seiner Wiedergabe

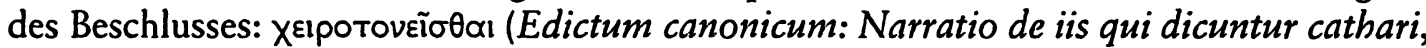
CPG 2678.3, PG 65,44) sowie die Epistula de eis qui ad Ecclesiam accedunt (CPG 5983, s. dazu Anm. 71) Z. 19f. (Text s. Anm. 75). Auch S.L. Greenslade, Schism in the Early Church, London ${ }^{2} 1964,150 f$. kommt zu dem Schluß, daß eine Neuordination gemeint ist.

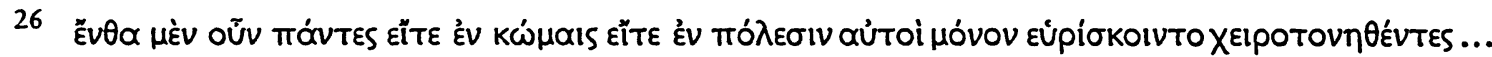
C Nic. (325), can. 8 (1,30,19-31,1 Joannou). Es ist bezeichnend für die andere Lage im Westen, daß Rufin, h.e. X 6 (967,9-17 Mommsen) bei seiner Übersetzung entscheidende Änderungen vornahm. Der hier zitierte Passus fehlt bei ihm ganz (wohl weil er sich eine derartige Situation nicht vorstellen konnte). Die Regel „Nicht zwei Bischöfe in einer Stadt", die im Original den Kanon abschließt, hat Rufin als nicht dem gleichen Themenkreis zugehörig empfunden; er macht daraus einen eigenen Kanon (Nr. 10 in seiner Numerierung). Damit ist der Skopus des Textes zerstört; der Sitz im Leben ist nicht mehr erkennbar.

C Nic. (325), can. 8 (1, 30,9-19 Joannou).

28 Vgl. B. Kötting, Art. Digamus, RAC 3, Stuttgart 1957, (1016-1024) 1020f. sowie ders., Die Bewertung der Wiederverheiratung (der zweiten Ehe) in der Antike und in der frühen

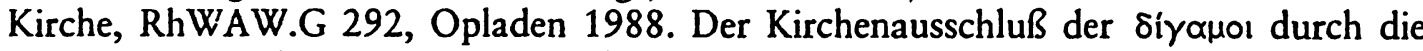
Novatianer wird von anderen Quellen bestätigt: Epiphanios, haer. 59,3 (GCS Epiphanius 2, 366,7-367,6 Holl); Theodoret, Interpretatio in xii epistulas s. Pauli (CPG 6209) zu 1Kor 7,40 (PG 82, 285B). Sokrates, h.e. V 22,60 berichtet interessanterweise, diese rigide Praxis sei eine Eigenart der phrygischen Novatianer. Vgl. zu diesem Thema G. Cereti, Divorzio, nuove nozze e penitenza nella Chiesa primitiva, StRic 26 , Bologna

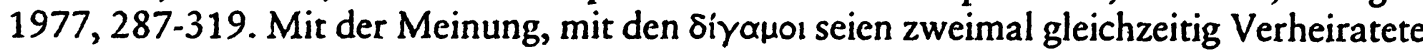
gemeint, steht Cereti allerdings allein (vgl. auch $\mathrm{H}$. Crouzel, Les digamoi visés par le Concile de Nicée dans son canon 8, Aug. 18, 1978, 533-546). tianische Taufe sei in Nikaia anerkannt worden, weiß ich nicht. Natürlich ist es richtig, 
übertretende Novatianer und Quartodezimaner ihren alten Glauben verurteilen müssen ${ }^{30}$. Sofern sie schon getauft waren, empfangen sie danach nur noch die Chrismasalbung und können ohne Wiedertaufe an der Eucharistie teilnehmen ${ }^{31}$.

III.

Die dritte, umfangreichste Gruppe von Quellen über die Novatianer sind die Schriften ihrer orthodoxen Gegner. Bei der Interpretation dieser Quellen ist erstens mit polemischer Verzeichnung zu rechnen und zweitens damit, daß gewisse antihäretische Vorwürfe topisch werden und nicht die Verhältnisse der betreffenden Häresie zu der Zeit und an dem Ort des Schreibers widerspiegeln. Darum müssen die wichtigsten Zeugnisse zunächst sorgfältig je für sich interpretiert werden, bevor eine zusammenfassende Auswertung versucht wird. Dabei soll besonderes Augenmerk auf die Zeugnisse aus dem kleinasiatischen und Konstantinopolitaner Bereich gerichtet werden.

Basileios von Kaisareia schließt insofern gut an die kirchenrechtlichen Texte an, als er die Novatianerfrage weitgehend unter juristischen Gesichtspunkten betrachtet, weshalb die einschlägigen Texte als „kanonische Briefe" in die Tradition der orthodoxen Kirche eingegangen sind. In Basileios' eigener Praxis im bischöflichen Amt im kappadokischen Kaisareia wird sich die Frage des Verhältnisses zu den Novatianern kaum gestellt haben. Weder durch den archäologischen Befund noch durch Sokrates oder eine andere Quelle erhalten wir einen Hinweis, daß es in Kappadokien Novatianer in nennenswerter Anzahl gegeben hat. Der Grund, aus dem sich Basileios mit dem Problem überhaupt auseinander-

daß dort „keine Wiedertaufe der Novatianer verlangt wird“ (Vogt, 251 Anm. 50), aber doch nur, weil von dem Problem überhaupt nicht die Rede ist. Wenn man mit Vogt, 190192, allerdings annimmt, daß die Kleriker nicht neu geweiht werden (s. dagegen Anm. 25), dann ist es in der Tat logisch zu vermuten, daß auch die Taufe anerkannt wird. Nur darf man dann eben nicht die Taufanerkennung als Argument für die Interpretation der Passage über die Weihe heranziehen (Vogt, 190) - sonst beißt sich die Katze in den eigenen Schwanz. Im übrigen bezeugt Basileios noch Ende des Jahrhunderts, daß die Frage der Taufanerkennung nicht einheitlich geregelt war (s. unten bei Anm. 35).

C Laod., can. 7 (2,133,1-15 Joannou). Die Erwähnung der Photinianer zwischen den Novatianern und den Quartodezimanern $(133,5 \mathrm{f}$.) ist textkritisch unsicher und aus inhaltlichen Gründen klar als spätere Einfügung zu erkennen, vgl. C.J. Hefele, Histoire des Conciles d'après les documents originaux, übers. v. H. Leclerq, Bd. 1/2, Paris 1907, 999f.

31 Zu dieser Praxis, die sich bald allgemein durchsetzen sollte, s. unten S. 269f. Der Sache nach berührt sich die Regelung eng mit einem Text, der als siebenter Kanon der Konstantinopolitaner Synode 381 in die Tradition eingegangen ist, doch stammt der Text weder von der Synode 381 noch ist er der Form nach überhaupt ein Kanon. Es handelt sich vielmehr um einen Ausschnitt aus einem Mitte des fünften Jahrhunderts in Konstantinopel verfaßten Brief (s. dazu unten bei Anm. 71). 
setzt, ist eine Anfrage seines Freundes Amphilochios von Ikonion - was wenig erstaunlich ist, denn genau aus dessen Gebiet ist eine starke novatianische Gemeinde durch die Inschriftenfunde gut belegt ${ }^{32}$. Die differenzierte Stellungnahme des Basileios beginnt mit einer terminologischen Aufschlüsselung, derzufolge die Novatianer nicht als Häretiker eingestuft werden, sondern - eine Stufe besser - als Schismatiker ${ }^{33}$. In bezug auf die konkrete Frage, um die es Amphilochios geht, ob nämlich die Taufe der Novatianer anzuerkennen sei oder nicht, folgt daraus, daß die häretische Taufe keinesfalls, die der Schismatiker hingegen unter bestimmten Umständen anzuerkennen $\operatorname{se}^{34}$. Die Schwierigkeit besteht nun darin, daß die Kirche in dieser Frage noch zu keiner einheitlichen Regelung gefunden hat, so daß Basileios rät, den jeweils landesüblichen Gebräuchen zu folgen ${ }^{35}$. Seine eigene Stellung ist allerdings die, daß die novatianischen Kleriker, auch wenn sie einmal rechtens und in der orthodoxen Kirche geweiht worden sind, durch ihren Abfall der Gabe des Heiligen Geistes verlustig gegangen und aus diesem Grunde keine gültige Taufe oder Weihe zu spenden in der Lage sind ${ }^{36}$. Dennoch ist er bereit, den Standpunkt der

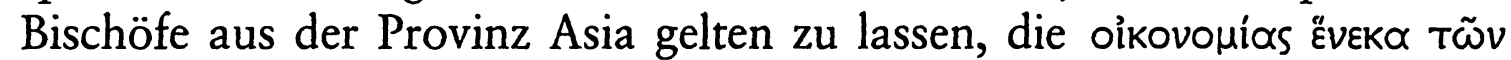
$\pi \circ \lambda \lambda \tilde{\omega} \nu$, aus der praktischen Erwägung heraus, daß es dort so viele Novatianer gibt, deren Taufe anerkennen ${ }^{37}$. In einem späteren Brief an Amphilochios hält Basileios an dieser Auffassung fest, betont jedoch, daß er im Falle der Enkratiten, Sakkophoroi und Apotaktiten nicht bereit sei, von seiner Praxis der Wiedertaufe abzugehen, auch wenn man in der Gegend des Amphilochios und auch in Rom anders darüber denke. Die Frage müsse einmal durch eine Bischofssynode eindeutig geklärt werden ${ }^{38}$.

32 Von Ikonion nach Laodikeia in Pisidien, von wo die meisten der in Anm. 8 angeführten Inschriften stammen, sind es nur etwa 50 Kilometer.

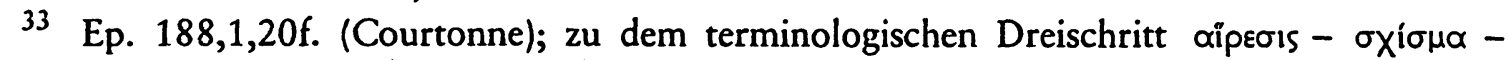

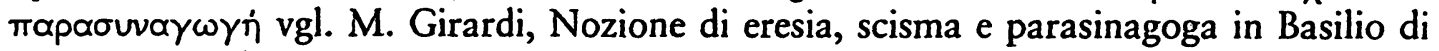
Cesarea, VetChr 17, 1980, 49-77. Die Stufe der Schismatiker ist offenbar eigens für die Novatianer eingefügt.

34 Ep. 188,1,25-27 (Courtonne).

35 Ep. 188,1,1-5 (Courtonne). Basileios spricht hier von einer früheren Behandlung der

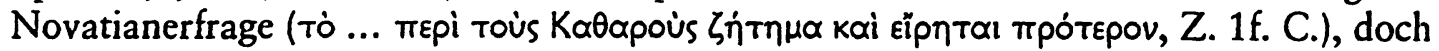
von einer solchen hat sich leider nichts erhalten.

Ep. 188,1,51-63 (Courtonne).

37 Ep. 188,1,63-65. Die Übersetzung von Y. Courtonne (Saint Basile, Lettres, 3 Bde., CUFr, Paris 1957-66) „pour se conformer aux dispositions prises par la plupart" scheint mir hier nicht das Richtige zu treffen.

38 Ep. 199,47,1-20. Die Passage gibt so, wie sie Courtonne abdruckt, vorzüglichen Sinn. In Z. 1 gegen alle Handschriften, einem Vorschlag der Mauriner folgend (PG 32, 729 nota 7), ein oủ einzufügen, entstellt dagegen den Zusammenhang, denn hier geht es Basileios ja gerade darum, die Gleichbehandlung aller besagten Häresien zu betonen. Es wäre nicht nötig, darauf weiter einzugehen, hätte nicht Vogt, Coetus (wie Anm. 1), 251 Anm. 50, den Vorschlag der Mauriner wieder aufgenommen. Zur Begründung verweist er auf die angebliche Taufanerkennung durch den nizänischen Kanon, an den Basileios hier gebunden sei, vgl. dazu jedoch Anm. 29. 
Trotz einer gewissen Unsicherheit und obwohl seine Haltung strenger ist als die der meisten seiner Amtsbrüder an anderen Orten, scheint Basileios den Novatianern unter den zahlreichen Sekten in Kleinasien mit dem größten Wohlwollen zu begegnen. Natürlich kann er ihre Ablehnung des Bußinstituts ${ }^{39}$ nicht teilen - im Gegenteil befürwortet er selbst ein überaus entwickeltes und differenziertes Bußwesen ${ }^{40}$-, doch ist auch seine Praxis verhältnismäßig rigide ${ }^{41}$. Speziell bei der Frage der Wiederverheirateten, bei der sich novatianische Praxis von der großkirchlichen unterschied, teilt Basileios die anderswo praktizierte laxere Handhabung nicht und belegt die zweite (und jede weitere) Ehe mit kirchlichen Strafen ${ }^{42}$.

Gregor von Nazianz, der gute Freund des Basileios, kommt von einem ganz ähnlichen Hintergrund und wird das Novatianerproblem vor seiner Wahl zum Bischof von Konstantinopel kaum als sehr dringend empfunden haben. Jedenfalls spielt es in seinen Schriften aus dieser Zeit keine Rolle ${ }^{43}$. Die verschiedenen Erwähnungen des Themas in Reden als Bischof der Hauptstadt zeigen jedoch, daß er es dort mit einer Novatianergemeinde von nicht nur marginaler Bedeutung zu tun hatte. Die meisten dieser Erwähnungen sind kurz und polemisch-abgrenzenden Charakters: Stolz und Angeberei werden den Novatianern vorgeworfen; der mit der Bezeichnung $k \propto \theta \alpha p o i$ verbundene Reinheitsanspruch wird bestritten ${ }^{44}$. Doch in der Epiphaniaspredigt In sancta lumina (or. 39) wird deutlich, daß Gregor auch zu einer differenzierteren Wahrnehmung des Problems in der Lage war, wenngleich dieser Text mit der für Gregor typischen, sehr geschliffenen Rhetorik gestaltet ist, was bei der Interpretation zu berücksichtigen ist $^{45}$. Der Hauptvorwurf gegen die Novatianer ist - selbstverständlich - die $\mathrm{zu}$ rigide Stellung in der Bußfrage. Diese Stellung ist unmenschlich, widerspricht dem Verhalten Jesu und anderen biblischen Vorbildern und läßt

$39 \mathrm{Da}$ er in der Buße die entscheidende theologische Differenz sieht, ergibt sich aus ep. 188,1,20f. (Courtonne).

40 Die hier zitierten kanonischen Briefe des Basileios sind eine der Hauptquellen für die Bußstufen in der östlichen Kirche, vgl. E. Schwartz, Bußstufen und Katechumenatsklassen, in: ders., Gesammelte Schriften, Bd. 5, Berlin 1963, (274-362) 316-322; B. Poschmann, Art. Bußstufen, RAC 2, Stuttgart 1954, 814-816.

Die von ihm verhängten Strafen auch für leichtere Vergehen sind teilweise drakonisch, vgl. B. Poschmann, Buße und letzte Ölung, HDG 4/3, Freiburg 1951, 50. Ep. 188,4. Besonders für die zum dritten Mal Verheirateten ist mit einem Kirchenausschluß von fünf Jahren eine ziemlich hohe Strafe vorgesehen (Z. 10f. Courtonne). Die in den folgenden Anm. angeführten Stellen stammen laut O. Bardenhewer, Geschichte der altkirchlichen Literatur, 5 Bde., Freiburg ${ }^{2} 1913-1932$, 3,173-177, sämtlich erst aus der Konstantinopolitaner Zeit.

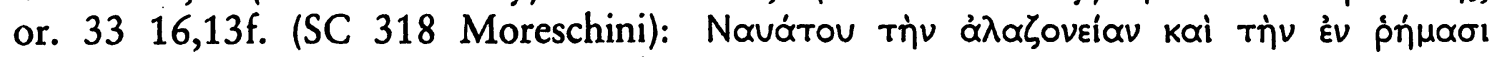

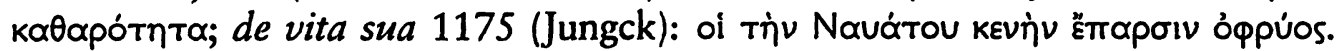
nias 381, möglicherweise 380 in Konstantinopel). 
Gregor von neuem Pharisäismus sprechen. Daneben zeigt sich aber auch ein weiterer Kontroverspunkt in der Praxis: Die Novatianer lehnten die Wiederverheiratung selbst ganz junger Witwen $a b^{46}$. Weiterhin ist die Bemerkung sehr aufschlußreich, daß zwar Unzucht, nicht aber Habsucht ( $\pi \lambda \varepsilon \circ v \varepsilon \xi i ́ \alpha)$ bei den Novatianern verpönt $\operatorname{sei}^{47}$. Es ist gewiß berechtigt, daraus zu schließen, daß zumindest manche Mitglieder der novatianischen Gemeinde recht begütert waren ${ }^{48}$.

Gregor schließt mit einem großen Appell, der zunächst wie freundschaftliches Werben klingt: „Kommt, stellt euch zu uns, den Menschen. Laßt uns gemeinsam den Herrn preisen! “ Den „Reinen“ ruft der Bischof zu: „Gebt auch uns von eurer Reinheit! " ${ }^{49}$ Diese Worte sind indessen nicht so konziliant, wie sie klingen mögen. Die angebliche Reinheit ist wenige Sätze zuvor als "Schwindel (Tũథos)“ beschimpft worden und wird hier mehr ironisch gemeint sein. Die Einladung zum gemeinsamen Gotteslob kann nach den vorhergehenden scharfen Vorwürfen nur als mehr oder minder unverblümte Aufforderung zur Konversion verstanden werden ${ }^{50}$. Es ist kaum möglich, bei diesem Text durch die rhetorische Gestaltung hindurch zu erkennen, wie Gregors Verhältnis zu den Novatianern wirklich war. Auf jeden Fall aber wird deutlich, daß ihre Sondergemeinde in der Hauptstadt eine bedeutende Erscheinung war, auf die der orthodoxe Bischof einzugehen hatte. Möglicherweise läßt sich dem Text auch entnehmen, daß das Thema Konversion eine gewisse Aktualität hatte.

In einer ähnlichen Situation fand sich wenig später der aus Antiochien kommende Bischof Johannes Chrysostomos. Auch er wird in seiner Heimat wenig Gelegenheit gehabt haben, sich mit den Novatianern auseinanderzusetzen. Auch bei ihm finden sich in der Zeit als Konstantino-

(Morchini).

So auch Vogt, Coetus (wie Anm. 1), 242. Außerdem möchte Vogt, 241, aus dieser Predigt eine Ablehnung der Märtyrerverehrung durch die Novatianer ableiten. Doch die rheto-

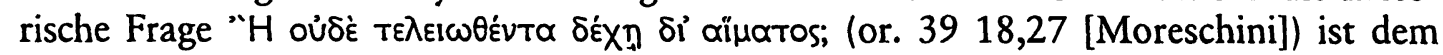
Zusammenhang nach ganz eindeutig ausschließlich auf Petrus zu beziehen, dessen Beurteilung wegen der Verleugnung Jesu offenbar zwischen Großkirche und Novatianern kontrovers war. Von Märtyrerverehrung im allgemeinen ist hier keine Rede. Darum kann auch Gregor nicht mit der später von Eulogios (s. unten Anm. 82) bezeugten Ablehnung des Reliquienkultes durch die Novatianer in Verbindung gebracht werden (gegen Vogt, 241 Anm. 17).

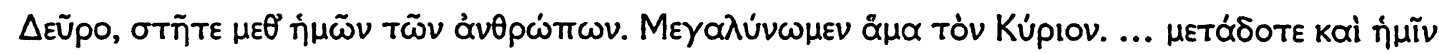

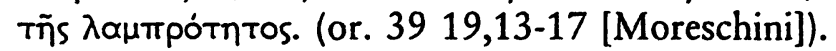

50

Für Vogt, Coetus (wie Anm. 1), 242, könnten die in der vorigen Anm. zitierten Worte „Programm aller oekumenischen Aktivität sein“. Das könnten sie in der Tat, nur scheint mir in diesem konkreten Falle der Kontext zu wenig berücksichtigt. Darum kann ich der Auffassung, daß sich hier „bestätigt, was Sokrates über das vergleichsweise gute Verhältnis zwischen Novatianern und Katholiken berichtet", nur insoweit zustimmen, als deutlich wird, daß die Novatianer ein ernstzunehmendes und ernstgenommenes Gegenüber waren. 
politaner Bischof ${ }^{51}$ verschiedene Äußerungen zum Thema, doch im Unterschied zu Gregor ist seine persönliche Stellung klar: Über die rhetorische Polemik hinaus spiegelt sich in seinen antinovatianischen Äußerungen kompromißlose Ablehnung.

In einer an prominenter Stelle, nämlich in der Apostelkirche, vor prominentem Publikum vorgetragenen Predigt vom Januar $399^{52}$ wiederholt Johannes die auch schon von anderen geäußerte Kritik am Reinheitsanspruch der Katharer. Doch in seinem Munde erfährt diese Kritik eine wesentliche theologische Vertiefung. Die Novatianer werden dem Anspruch nicht nur deshalb nicht gerecht, weil ja doch immer wieder die Dinge vorkommen, die sie zu vermeiden behaupten, sondern viel grundsätzlicher: Këin Mensch kann auch nur einen einzigen Tag sich selbst „rein“ halten, frei von Sünden. Das setzt einen vertieften Sündenbegriff voraus, der nicht nur Mord und Unzucht umschließt (um solche Dinge ging es den Novatianern in der Praxis), sondern auch Alltagssünden wie Neid, Lüge, Verleumdung. Darum bleibt der Christ stets, auch unabhängig vom institutionalisierten kirchlichen Bußwesen, auf Vergebung und Menschenfreundlichkeit angewiesen (die $\phi \imath \lambda \alpha \nu \theta \rho \omega \pi i \alpha$ ist in diesem $\mathrm{Zu}$ sammenhang ein Schlüsselbegriff $)^{53}$.

Auch auf exegetischem Gebiet tritt Johannes Chrysostomos den Novatianern entgegen. Diese hatten sich besonders auf den Hebräerbrief berufen $^{54}$; so überrascht es nicht, daß Johannes gerade bei der Auslegung dieses

Zur Konstantinopolitaner Provenienz der im folgenden zu besprechenden Texte s. die Anm. 52, 55 und 56.

Diese Predigt (Aduersus catharos, CPG 4441.6) ist bei Migne (PG 63,491-494) nach Montfaucon nur teilweise abgedruckt, weil in der zugrundeliegenden Handschrift (Ottobon. gr. 431) nur teilweise erhalten. Jedoch wurde von A. Wenger 1955 eine Handschrift mit dem vollständigen Text entdeckt (Ath. Stavron. 6, fol. $79^{\mathrm{v}}-84$, vgl. A. Wenger, La tradition des œuvres de Saint Jean Chrysostome, REB 14, 1956, [5-47] 38f., dort auch zu den Einleitungsfragen [Zeit und Ort der Predigt]). Eine Edition des Textes ist von M. Aubineau in der Reihe Sources Chrétiennes geplant (vgl. M. Aubineau, Publication des Undecim novae homiliae de Saint Jean Chrysostome [PG 63,461-530]. Édition critique, comblement des lacunes, additions de deux inédits, in: StPatr 22, hg. v. E.A. Livingstone, Löwen 1983, 83-88). Ich danke Père Michel Aubineau, daß er mir Kopien der Handschrift zur Verfügung gestellt hat. In dem bei Migne fehlenden Textstück geht Johannes von den enkomiastischen Aussagen über Theodosios I. (bis fol. 80 $\mathrm{b}$ b) zu einer drastischen Schilderung des Elends der Verworfenen über (bis fol. 81 ${ }^{\mathrm{r}} \mathrm{a} 26$ ), um von dort aus die Angewiesenheit der Menschen auf Vergebung und Gnade zu betonen (bis fol. $81^{\mathrm{v}} \mathrm{a} 2$ ). Dieses Thema führt ihn zu der ausführlichen antinovatianischen Polemik (bis fol. $83^{\mathrm{v} a} 22$ und weiter bei Migne Sp. 492). Anhand einer Reihe biblischer Beispiele (Jesaja, David, Abraham, die drei Jünglinge, Paulus) zeigt er, daß ein Reinheitsanspruch, wie er ihn den Novatianern unterstellt, auch von den größten Heiligen nicht aufrecht erhalten werden kann. Die theologische Schlußfolgerung ist bei Migne abgedruckt (s. gleich im folgenden).

53 PG 63, 492, die or. 39 18,10-15; 39 19,1-12 (Moreschini); Epiphanios, haer. 59, 6,2 (2, 370,13-15 Holl); Severian von Gabala, de paen. 5 (PG 59, 765, s. Anm. 61). 
Briefes wieder auf das Thema zu sprechen kommt. Aus Hebr 10,26 („Nach der Erkenntnis der Wahrheit gibt es für die Sünden kein Opfer mehr") ist nicht zu folgern, daß es nach der Taufe keine Vergebung mehr gibt (so scheint die novatianische Auslegung gelautet zu haben), sondern daß es keine zweite Taufe, keine zweifache Teilhabe am Kreuz Christi gibt. Sehr wohl aber bedarf es der guten Werke, um Vergebung für die Sünden zu erlangen ${ }^{55}$. Im Zusammenhang der Auslegung von Eph 4,28 tritt mehr beiläufig wieder die Bestreitung des Reinheitsanspruchs auf ${ }^{56}$.

Die ablehnende Haltung des Johannes Chrysostomos gegenüber den Novatianern ist auf dem Hintergrund seines positiven Verhältnisses zur Buße zu verstehen. Sein Zugang dazu ist nicht so sehr ein kirchenrechtlicher (wie bei Basileios), sondern eher ein seelsorgerlicher ${ }^{57}$. In verschiedenen Predigten, die vermutlich teilweise noch aus der antiochenischen Zeit stammen ${ }^{58}$, hatte er seinen Zuhörern den Wert dieser Einrichtung eingeschärft. Das von Sokrates dem Johannes zugeschriebene Wort $\chi^{\imath} \lambda$ เókıs

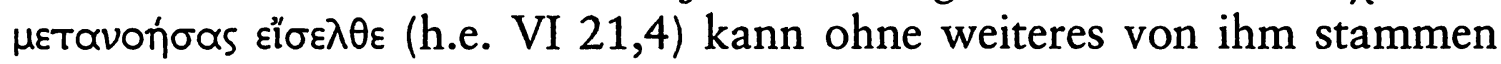
und findet, wenn auch keine wörtliche, so doch sachliche Parallelen in den Bußpredigten $^{s 9}$.

55 In epistulam ad Hebraeos argumentum et homiliae 1-34 (CPG 4440), hom. 20,1 (PG 63,143 f.)..Die Homilienreihe zum Hebräerbrief stammt laut Montfaucon (PG 63,5) sicher aus Konstantinopel (vgl. auch Bardenhewer, Geschichte [wie Anm. 43], 3,338).

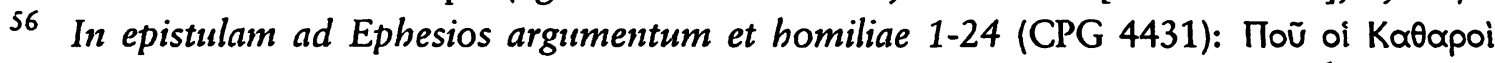

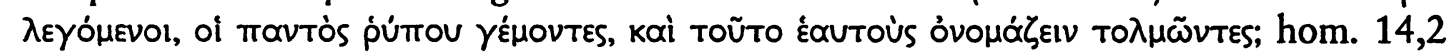
(PG 62,102). Wann und wo diese Predigtreihe enstanden ist, ist unklar. Während sich Montfaucon (PG 62,6) für Antiochien ausspricht, plädiert G. Rauschen, Jahrbücher der christlichen Kirche unter dem Kaiser Theodosius dem Großen, Freiburg 1897, 528f. vorsichtig für die Konstantinopolitaner Zeit.

57 Vgl. die Ausführungen von A.M. Ritter, Johannes Chrysostomus, Geschichte der Seelsorge in Einzelporträts, hg. v. C. Möller, Bd. 1, Göttingen 1994, (153-170) 166-169 über Johannes als Seelsorger.

58 Die Reihe von Bußpredigten PG 49,277-350 ist nicht etwa in dieser Zusammenstellung von den Handschriften überliefert, sondern von Montfaucon unter thematischen Gesichtspunkten gesammelt. Aus diesem Grunde ist für jede gesondert zu diskutieren, ob sie echt ist und aus welcher Zeit sie stammt.

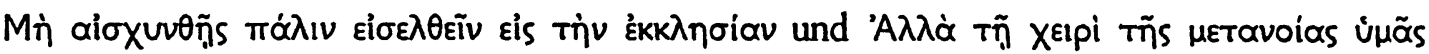

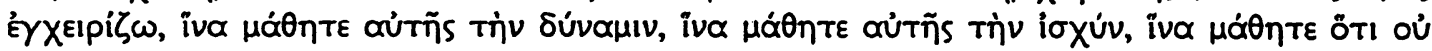

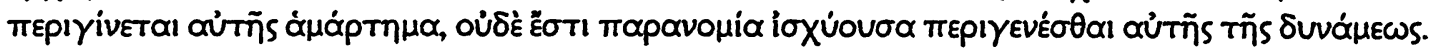

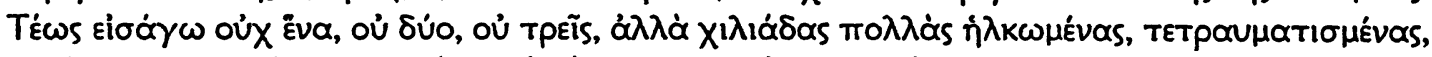

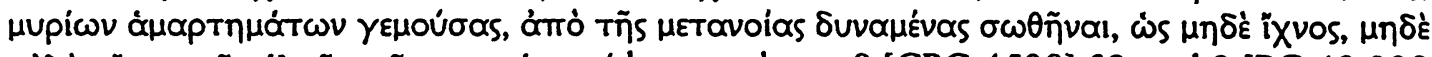

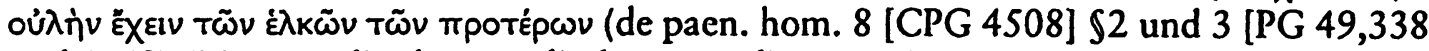
und 340]). Diese Predigt könnte direkt gegen die Novatianer gerichtet sein, es wird aber nicht explizit gesagt (vgl. z.B. Sp. 344!). Montfaucon (PG 49,273-276) hat allerdings Zweifel an der Echtheit dieser Predigt geäußert, sie aber dennoch mit in der Reihe der echten Bußpredigten abgedruckt (Non sine aliquo scrupolo eas inter germana Chrysostomi opera relinquimus, vgl. auch J.A. de Aldama, Repertorium pseudochrysostomicum, Documents, études et répertoires publiés par l'Institut de Recherche et d'Histoire des Textes 10, Paris 1965, Nr. 88). Auch eine Passage aus einer noch in Antiochien (Montfaucon, PG 62,663f.) gehaltenen Homilie über den Titusbrief würde gut auf die Nova-

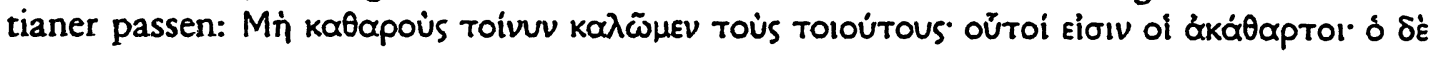


Für den Novatianismus in Konstantinopel geben auch Äußerungen des Severian von Gabala ein interessantes Zeugnis. In einer nur armenisch erhaltenen Osterpredigt, die sich explizit gegen die Novatianer richtet, polemisiert er gegen diejenigen, die sich mit ihrem Ostertermin nach den Juden richten, und bezeugt damit, daß es bei den Novatianern eine solche Gruppe gab ${ }^{60}$. Weiterhin hat sich unter den spuria des Johannes Chrysostomos eine Bußpredigt (De paenitentia, CPG 4614) mit scharfer, antinovatianischer Polemik erhalten, die wohl auch von Severian stammt ${ }^{61}$. Darin wird die Möglichkeit und Notwendigkeit der Buße betont, was schließlich in dem pointierten Vorwurf gipfelt, Gott habe den Schuldschein des Menschen zerrissen, doch Novatian füge die Fetzen wieder zusammen. Aber nicht Novatian sei es, der zum Gericht über Lebende und Tote wiederkommen wird. Nicht ihm werde beim Gericht ein dreizehnter Thron neben den Aposteln errichtet ${ }^{62}$. Das ist, wenn möglich, noch schärfer als die Äußerungen des Johannes. In der Ablehnung des Novatianismus waren sich die beiden einander sonst so feindlichen Bischöfe also durchaus einig.

Eine weitere Predigt, deren Verfasser unbekannt (und deren Herkunft aus Konstantinopel auch nicht erwiesen) ist ${ }^{63}$, gibt den konkretesten Einblick in die Differenz in der pastoralen Praxis. Die Predigt ist eine rhetorisch glänzende Apologie des kirchlichen Bußwesens. Naheliegenderweise sind die Gegner, mit denen sie sich dabei hauptsächlich auseinandersetzt, die Novatianer, die offenbar die Vollmacht des Priesters zur Sündenvergebung mit dem Argument bestritten hatten, daß doch auch der Priester ein Mensch und daher sündig sei. Dagegen beruft sich der Prediger auf den Auftrag und die Vollmacht zur Sündenvergebung, die Jesus den Jüngern gegeben habe, obgleich doch auch sie - insbesondere Petrus - Sünder

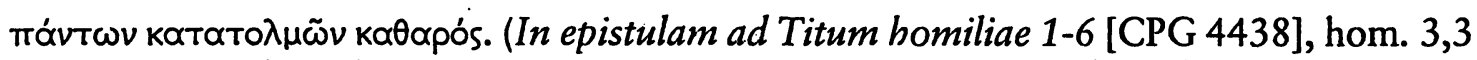
[PG 62,680, vgl. auch schon Sp. 679]). Dem Zusammenhang nach sind aber Juden bzw. judaisierende Christen gemeint.

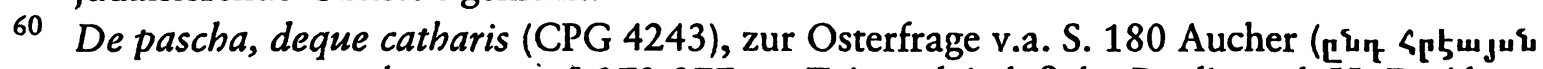
qumply wn.utน, s. dazu unten S.273-277, zu Zeit und Anlaß der Predigt vgl. H.-D. Altendorf, Untersuchungen zu Severian von Gabala, Diss. theol. Tübingen 1957, 176-181.

Das hat zuerst B. Marx, Severiana unter den Spuria Chrysostomi bei Montfaucon-Migne, OCP 5, 1939, (281-367) 332-337, vermutet (gibt aber selber zu, daß er „keine besonders frappanten Beweise erbringen "könne, S. 333), anders, aber auch ohne durchschlagende Argumente Altendorf, Untersuchungen (wie Anm. 60), 72-74 (vgl. de Aldama, Repertorium [wie Anm. 59], Nr. 530). Die Verwandtschaft mit der allgemein für severianisch gehaltenen Bußpredigt De paenitentia et compunctione (CPG 4186, vgl. Altendorf 253, de Aldama Nr. 395, S.J. Voicu, Nuove restituzioni a Severiano di Gabala, RSBN 20/21, 1983/84, [3-24] 6) macht seine Verfasserschaft aber doch recht wahrscheinlich; insbesondere ein Motiv, das in beiden Predigten begegnet, ist sehr charakteristisch: Die Tränen des Büßenden sind wie ein zweites Taufbad (入outpóv), PG 49,331 bzw. PG 59,764.

62

De ieiunio, de Dauide (CPG 4676, PG 62,759-764, vgl. de Aldama, Repertorium [wie Anm. 59], Nr. 203). Die Predigt ist unter dem Namen des Johannes Chrysostomos überliefert und von Montfaucon - wohl wegen ihrer klerikalen Tendenz - unter die spuria eingereiht. 
gewesen seien. Der theologische Grund dafür liege darin, daß nicht ein Mensch, sondern Gott es sei, der Sünden vergibt ${ }^{64}$. Dieser Grundsatz wurde natürlich auch von den Gegnern nicht bestritten ${ }^{65}$, doch setzt die Predigt voraus, daß es in der Großkirche ein entwickeltes Bußwesen gab, das die Novatianer in dieser Form nicht akzeptieren konnten, weil ihrer Auffassung nach eine zweite Buße nach der Taufe nicht möglich ist und die Vergebung schwerer Sünden nach der Taufe die Vollmacht des kirchlichen Aintes überschreitet ${ }^{66^{\circ}}$.

Ebenso aufschlußreich durch ihren Inhalt wie problematisch durch ihre Überlieferungslage sind einige kurze Texte über die Novatianer, die in der armenischen Übersetzung des Sokrates dem Text der Kirchengeschichte zugesetzt sind. Vermutlich stammen diese Zufügungen von einem Konstantinopolitaner Interpolator kurze Zeit nach Sokrates, der zwar selbst orthodox war, aber gut über die Novatianer Bescheid wußte ${ }^{67}$. In dem theolo-

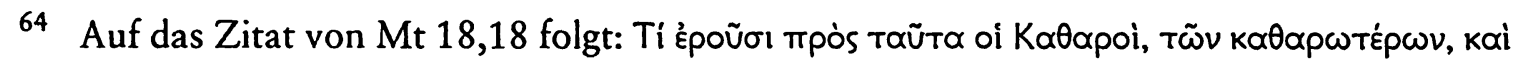

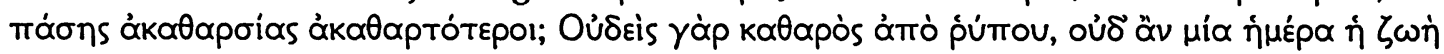

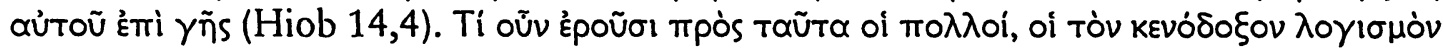

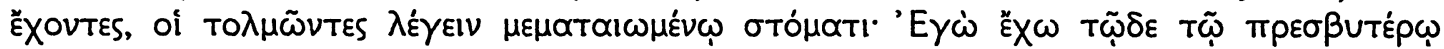

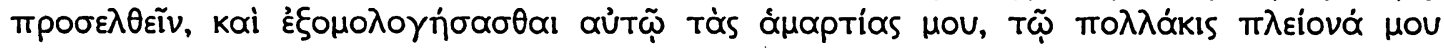

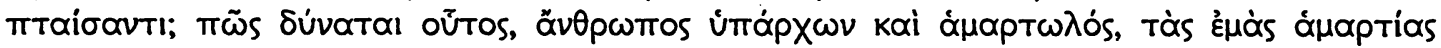

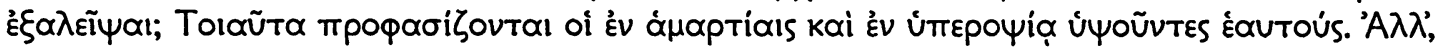

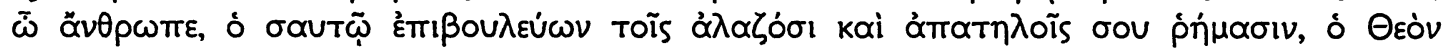

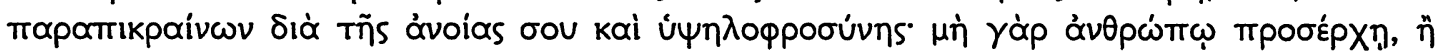

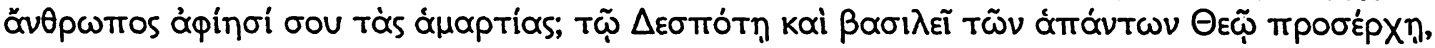

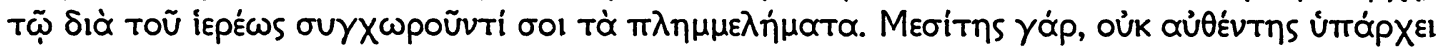
$\delta$ iepeús. (PG 62, 760f.) Im folgenden werden die Novatianer auch explizit genannt. Die Predigt ist sehr aufschlußreich für die Geschichte des Bußwesens im Osten (es ist die m.W. deutlichste Erwähnung des Elementes der Beichte bei der Buße) und wohl nur deshalb nicht angemessen ausgewertet, weil über Herkunft und Verfasser nichts bekannt ist.

65 Im Gegenteil ist damit eine wichtige novatianische Bekenntnisformel angesprochen, vgl. Wallraff (wie Anm. 5), 234 Anm. 113.

66 Die Predigt setzt also eine Situation voraus, die genau in die von Sokrates geschilderte Kontroverse um das großkirchliche Bußpriesteramt hineinpassen würde (h.e. V 19, vgl. dazu Wallraff [wie Anm. 5], 241-245). Leider fehlt ein konkretes Indiz, um einen solchen Sitz im Leben zu erweisen.

67 Es handelt sich um Zusätze zu Sokrates, h.e. VII 17,15, VII 25,19 und VII 39,10 (abgedruckt in: Sokratay Sk'olastikosi Ekelec'akan Patmowt 'iwn, t'argmaneac' P'ilon Tirakac'i, hg. v. M. Têr-Movsêsean, Vałaršapat 1897, 601, 637 und 671f.). Englische Übersetzungen dieser Texte liegen vor bei F.C. Conybeare, A Collation of the History of Socrates Scholasticus, Books IV-VII, with the Old Armenian Version and with the Latin Version of Epiphanius Scholasticus as Preserved in the Historia Tripartita of Cassiodorus, JP 34, 1918, (47-77) 69, 72 und 76, die letzten beiden wieder abgedruckt bei Hansen (wie Anm. 2) im Apparat z.St. Die Frage nach Herkunft und Verfasserschaft dieser Texte möchte ich an anderer Stelle ausführlicher untersuchen. Jedenfalls ist leicht zu erkennen, daß die Stücke einerseits nicht echten Sokrates-Text darstellen (und daher als von ihm unabhängiges Zeugnis gelten können), andererseits von jemandem geschrieben sein müssen, dem die Konstantinopolitaner Novatianer eine Realität aus eigener Erfahrung waren (s. die folgenden Anm.). Daß die Texte in der Forschung noch nicht die ihnen gebührende Aufmerksamkeit gefunden haben, liegt ohne Zweifel an ihrem entlegenen Publikationsort (vor dem Wiederabdruck bei Hansen). 
gischen Streitgespräch zwischen den Bischöfen Attikos und Asklepiades läßt der Interpolator nicht den Novatianer Asklepiades das letzte Wort haben, sondern fügt eine Erwiderung des orthodoxen Attikos an, in der von einer sehr praktischen Seite aus Kritik an den Novatianern geübt wird. Wie schon bei Gregor begegnet der Vorwurf, daß sie zwar Unzucht, nicht aber Habsucht verurteilten, doch wird hier auch der Hintergrund explizit angesprochen: der Reichtum und die gehobene soziale Stellung mancher Mitglieder der Gemeinde ${ }^{68}$. Außerdem wird deutlich, daß die geforderte Strenge in der Praxis nicht immer durchgehalten wurde und so zu einer gewissen Verlogenheit führte ${ }^{69}$. Andererseits bezeugt der Interpolator auch die Nähe der Novatianer zur Großkirche, indem er sie als "orthodox" bezeichnet und vor allen Dingen ihrer Hauptkirche in Konstantinopel große Verehrung entgegenbringt ${ }^{70}$.

Für die Praxis des Umgangs mit novatianischen Übertretern in Konstantinopel ist ein Brief aufschlußreich, der dort vermutlich um die Mitte des fünften Jahrhunderts geschrieben worden ist ${ }^{71}$. Darin wird festgelegt,

"Avarice, to wit cupidity, this many of your (sect) are found to have. I mean that some (of you) tolerate (lit. admit) avarice as being supporters of grandees, while others reject because of fornication." (Hansen [wie Anm. 2] im App. zu h.e. VII 25,19 nach Conybeare, Collation [wie Anm. 67], 72). Vgl. auch die Erläuterung von Conybeare (zu

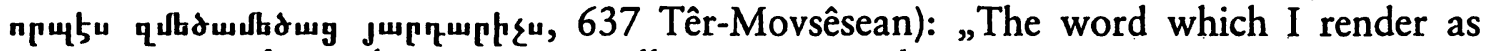
ssupporters' (of grandees) more usually means sregulators', sconstitutorss."

69 „... this when they know it (?), but if not, through forgetfulness ... It is that you are holden by fear and shame of men." (Hansen [wie Anm. 2] im App. zu h.e. VII 25,19 nach Conybeare, Collation [wie Anm. 67], 72). Der Sinn dieses Zusatzes ist im übrigen nicht überall ganz klar („somewhat obscure here and there“, Conybeare). Ob etwa das offensichtliche Mißverständnis des Schlußsatzes („... for he had come to visit Atticus“, wobei "he“ auch schon Attikos ist) schon auf den ungeschickten Interpolator zurückzuführen ist, muß offenbleiben.

70 „For truly is the spot holy ... Wherefore then we also together with the Novatiani that are orthodox there send up prayers and adoration to God who loveth mankind." (Hansen [wie Anm. 2] im App. zu h.e. VII 39,10 nach Conybeare, Collation [wie Anm. 67], 76). Hier wird gleichermaßen die Orthodoxie des Interpolators wie seine novatianerfreundliche Stellung deutlich.

71 Diese Epistula de eis qui ad Ecclesiam accedunt (CPG 5983) wirft eine Reihe von Fragen auf, um die sich eine (leider etwas verworrene) Forschungsdiskussion rankt. Der Brief (genauer: das Brieffragment, denn Eingang und Schluß fehlen) ist auf griechisch (ediert von I.B. Pitra in: Iuris ecclesiastici Graecorum historia et monumenta, Bd. 2, Rom 1868, 187 f., wiederabgedruckt bei F. Diekamp, Gennadius von Konstantinopel, in: ders., Analecta Patristica. Texte und Abhandlungen zur griechischen Patristik, OrChrAn 117, Rom 1938, [54-108] 83 [im folgenden: G]) und in zwei unabhängigen syrischen Übersetzungen erhalten (ediert von F. Schulthess in: Die syrischen Kanones der Synoden von Nicaea bis Chalcedon nebst einigen zugehörigen Dokumenten, AGWG.PH 10,2, Berlin $1908,145[=S]$ und F. Nau, Littérature canonique syriaque inédite, ROC 14, 1909, [1-49 und 113-130] 119f., letztere nur in französischer Übertragung [= N]), ein Ausschnitt darüber hinaus auch auf griechisch als Kanon 7 der Konstantinopolitaner Synode 381 (1,53f. Joannou [ $=\mathrm{K}]$ ). In allen diesen Versionen wird aber nicht deutlich, wer den Brief wann geschrieben hat. $\mathrm{Da}$ die Überschrift in allen Fassungen die Angabe ớrtò

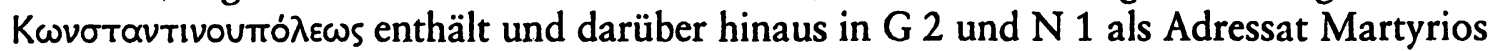
von Antiochien erwähnt wird, hat man das Dokument auf 459-471 datiert und den damaligen Patriarchen von Konstantinopel Gennadios als Verfasser angenommen (Pitra 
daß die Novatianer und Sabbatianer ${ }^{72}$ beim Übertritt zur katholischen Kirche einen schriftlichen Widerruf vorlegen und die Myronsalbung emp-

181; Diekamp 99-103, dem die CPG folgt). Dagegen hat E. Schwartz, Die Kanonessammlungen der alten Reichskirche, in: ders., Gesammelte Schriften. Bd. 4, Berlin 1960, (159-275) 164-166, an dieser Zuschreibung gezweifelt. Hauptargument dafür ist die ausgezeichnete Beobachtung, daß im Zusammenhang der vielen Konversionen von Novatianern und Quartodezimanern im lydischen Philadelphia (s. Anm. 76) von einem Presbyter Antonios berichtet wird, der zu diesem Zweck von Konstantinopel anreiste (ACO I/1/7, 96,7). Nun kann es kaum einem Zweifel unterliegen, daß dieser Antonios identisch ist mit dem gleichnamigen Presbyter, dem der Briefschreiber die Verfahrensweise bei Konversionen mitteilt (G 5). Daraus schloß Schwartz, daß der Brief nicht von, sondern nach Konstantinopel geschrieben sei, und zwar von dem philadelphischen Bischof Theophanios an Nestorios. Weil der Name des Empfängers anstößig war, habe man ihn später beseitigt. Dagegen kann Diekamp (p. 99) an der klassischen Sichtweise nur deshalb festhalten, weil ihm die Ergebnisse von Schwartz entgangen sind. E. Honigmann, Trois mémoires posthumes d'histoire et de géographie de l'Orient chrétien, hg. v. P. Devos, SHG 35, Brüssel 1961, 75-80 (der wiederum Diekamp nicht beachtet), versuchte, die Schwartzsche These dahingehend zu modifizieren, daß der Brief nicht von Philadelphia, sondern von Ephesos nach Konstantinopel geschrieben ist, jedoch mit unzureichenden Argumenten (selbst wenn mit dem in G 10 erwähnten Johannes nicht Chrysostomos, sondern der Evangelist gemeint sein sollte: Es wird ja der Empfänger und nicht der Absender als „Abkömmling des Johannes“ bezeichnet). Nun könnte man es bei Schwartz' Rekonstruktion belassen, sprächen nicht auch gegen sie gewichtige Argumente: Erstens ist Schwartz die Existenz der Texte $\mathrm{G}$ und $\mathrm{N}$ entgangen (so auch schon in ByZ

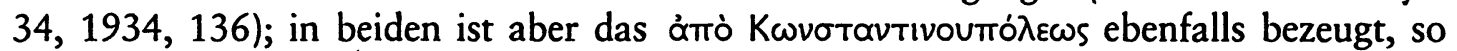
daß es nicht mehr so einfach ist, sich darüber hinwegzusetzen. Zweitens: Wie wahrscheinlich ist es, daß schon Anfang des fünften Jahrhunderts ein Bischof in Lydien von

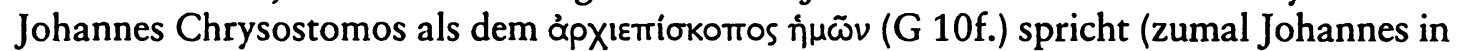
Kleinasien mancherorts eher unbeliebt war, vgl. etwa Sokrates, h.e. VI 11,8-11; Sozomenos, h.e. VIII 6,9)? Drittens: Sollte der Patriarch der Hauptstadt eigens einen Presbyter nach Philadelphia geschickt haben, um Direktiven über die Konversion von Häretikern einzuholen? Schließlich wäre es kaum zu verstehen, warum eine ganze Liste von unterschiedlichsten Häresien (G 11-13, s. die folgende Anm.) aufgeführt werden muß, wenn der Brief anläßlich eines speziellen Konversionsfalles von Quartodezimanern und Novatianern geschrieben sein sollte. So ist es also, auch wenn die Identifikation des Antonios richtig ist, wahrscheinlicher, daß der Brief von Konstantinopel als nach dorthin geschrie-

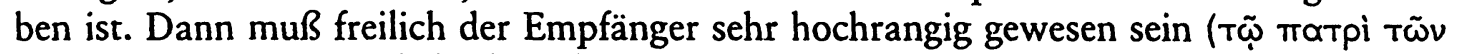

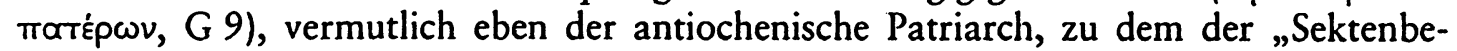
auftragte" Antonios mit Informationen über die Praxis der Konstantinopolitaner Kirche geschickt wurde. Ob es sich dabei wirklich um Martyrios (so G 2 und N 1) handelte (was bedeutete, daß Antonios noch mindestens 30 Jahre nach der Bezeugung durch die Konzilsakten im Amt gewesen sein muß - nicht unmöglich, aber recht unwahrscheinlich) oder einen früheren antiochenischen Bischof, muß offenbleiben. Eventuell könnte der Verfasser sogar Nestorios sein (dafür sprächen seine antiochenischen Beziehungen, die seine Nachfolger nicht hatten). In jedem Fall kann der Text als Zeugnis für den Umgang mit den Novatianern in Konstantinopel um die Mitte des fünften Jahrhunderts in Anspruch genommen werden.

P. Allen, The Use of Heretics and Heresies in the Greek Church Historians. Studies in Socrates and Theodoret, in: Reading the Past in Late Antiquity, hg. v. G. Clarke, Rushcutters Bay 1990, (265-289) 285 Anm. 9, ist nicht gut beraten, sich bei der Interpretation dieses Textes an Vogt, Coetus (wie Anm. 1), 248-256 anzuschließen, dem die Texte $\mathrm{G}, \mathrm{S}$ und $\mathrm{N}$ (sowie die gesamte Forschungsdiskussion) entgangen sind und der darum zu dem abwegigen Ergebnis kommt, es handele sich um einen auf dem Trullanum im Jahre 691 formulierten Kanon (can. 95 [1,230,7-233,7 Joannou]). Der Text dort gibt sich aber leicht als von $\mathrm{K}$ abhängig zu erkennen. 
fangen müssen, ohne aber neu getauft zu werden ${ }^{73}$. Das entspricht der von Basileios bezeugten, wenn auch nicht geteilten, westlichen Auffassung (wie auch der der laodikenischen Synode). Der theologische Grund für die Salbung liegt darin, daß die Novatianer die postbaptismale Taufsalbung, die dem Ritus der Großkirche im Osten im Laufe des vierten Jahrhunderts zugewachsen war, nicht vollzogen, so daß dieses Element der Initiation beim Übertritt nachgeholt werden mußte ${ }^{74}$. Weiterhin erfahren wir aus dem Brief, daß novatianische Ordinationen zwar nicht anerkannt werden, doch Kleriker werden nach der Konversion auf den gleichen Grad geweiht, den sie auch in der novatianischen Kirche innehatten, also eine Bestätigung des nizänischen Kanons ${ }^{75}$. Die hier beschriebene Praxis scheint sich allgemein durchgesetzt zu haben, weshalb der einschlägige Passus des Briefes in verschiedene Kanonessammlungen eingegangen ist und unter anderem nachträglich als Kanon 7 den Beschlüssen der Konstantinopolitaner Synode 381 hinzugefügt worden ist. In den Akten des Konzils von Ephesos 431 ist eine Reihe von Übertritten nach dem hier beschriebenen Muster breit dokumentiert ${ }^{76}$.

72 Übereinstimmend werden in K 53,12f., S 8 und N 15 neben den Novatianern die Sabbatianer genannt - m.E. Grund genug, um zu vermuten, daß sie in $\mathrm{G}$ ausgefallen sind (und nicht in den anderen Zeugen hinzugefügt). Auch das wäre ein Hinweis auf Konstantinopolitaner Provenienz, denn diese Abspaltung gab es nur dort (s. S. 273-277). Außerdem sind die Arianer, Makedonianer, Apolinaristen genannt, in K 53,14 ferner eine mit ápıбтєрoí bezeichnete Gruppe. Ein geistreicher Interpretationsvorschlag für diese rätselhafte Benennung bei Vogt, Coetus (wie Anm. 1), 254-256.

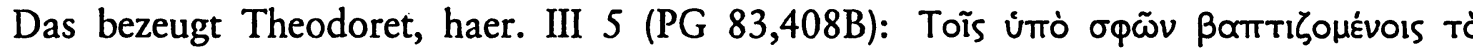

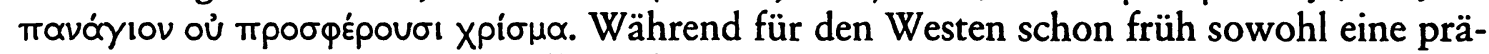
als auch eine postbaptismale Salbung bezeugt ist, gab es im Osten (Syrien) zunächst nur eine Salbung vor der Taufe (vgl. G. Kretschmar, Die Geschichte des Taufgottesdienstes in der alten Kirche, in: Leit. 5, Kassel 1970, [1-348] 101-109; B. Botte, L'onction postbaptismale dans l'ancien patriarchat d'Antioche, in: Miscellanea liturgica in onore di sua eminenza il cardinale Giacomo Lecaro, Bd. 2, Rom 1967, [795-808] 796f.; B. Kleinheyer, Sakramentliche Feiern. I. Die Feiern der Eingliederung in die Kirche, GDK 7,1, Regensburg 1989, 51f.; B. Varghese, Les onctions baptismales dans la tradition syrienne, CSCO.Sub 82, Löwen 1989, 113-115). Die von den Novatianern nicht mitvollzogene Entwicklung gegen Ende des vierten Jahrhunderts wird in der Großkirche durchaus auch unter dem Druck der zunächst strittigen Frage, was mit Konvertiten zu geschehen habe (vgl. Basileios vs. Synode von Laodikeia), zustande gekommen sein. Die nachgeholte, postbaptismale Salbung bot eine willkommene Möglichkeit, einen Ritus zur Geistausgießung zu vollziehen, ohne neu zu taufen (so Botte, 803-808, und nach gründlicher Prüfung allen Materials Varghese 120-126, vgl. auch Kleinheyer, 95, sowie Kretschmar, 192-198, zu weiteren theologischen Motiven). Dafür spricht u. a., daß die

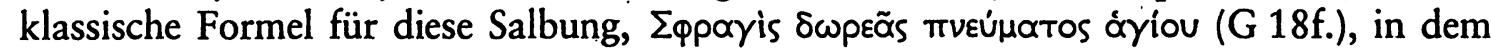
hier besprochenen Brief zuerst bezeugt ist, vgl. Kleinheyer, 90f. und Varghese, 120 Anm. 36.

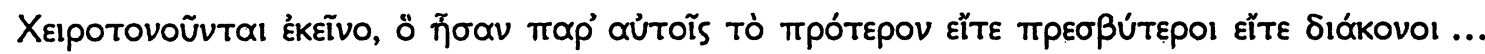
(G 19-21, in der Textgestalt folge ich hier Diekamp, nicht Pitra); dieser Teil ist nicht in den Kanon von Konstantinopel übernommen worden, wohl weil er angesichts der Regelung von Nikaia überflüssig erschien.

76 ACO I/1/7, 100,1-105,19; bei den meisten dieser Fälle handelt es sich um Quartodezimaner; Novatianer: 103,9.28.34. 
Die gleiche Praxis setzt der Presbyter Timotheos von Konstantinopel voraus, der Ende des sechsten Jahrhunderts in seinem Werk über die Wiederaufnahme von Häretikern die Novatianer und Quartodezimaner unter der Gruppe derer erwähnt, die nicht getauft, sondern nur gesalbt werden müssen ${ }^{77}$. Inwieweit aber das Problem damals wirklich noch virulent war, ist schwer zu sagen. Die konkreten Informationen, die Timotheos bietet, sind jedenfalls überwiegend Handbuchwissen ${ }^{78}$. Noch spätere Erwähnungen der Novatianer in Konstantinopel sind zweifellos nur noch „Selbstläufer“, also Ketzerkatalogeinträge, denen keine Realität mehr entsprach - ein Beispiel dafür, daß Feindbilder unter Umständen Feinde überleben ${ }^{79}$.

Noch etwas länger gehalten hat sich die novatianische Gemeinde in Alexandrien, die es auch schon zu Athanasios' und Theophils Zeiten gegeben haben muß $\beta^{80}$. Um die Wende vom sechsten zum siebten Jahrhundert ist dort von dem Patriarchen Eulogios ein großangelegtes antinovatianisches Werk verfaßt worden, das allerdings nur in den teilweise umfangreichen Auszügen des Photios überliefert ist ${ }^{81}$. Ein interessantes Detail darin ist die Tatsache, daß die Novatianer Eulogios zufolge die Verehrung von Reliquien ablehnten ${ }^{82}$.

Zusammenfassend läßt sich über die Verbreitung und soziale Stellung der Novatianer im vierten und fünften Jahrhundert aufgrund der behandelten Hauptquellen und einiger Nebenquellen Folgendes sagen: Das Kernland der Gemeinschaft lag in den ländlichen Gebieten des westlichen Kleinasien. Bezeugt sind Novatianer in den Provinzen Asien, Lydien, Phrygien, Pisidien, Lykaonien und Hellenopontos ${ }^{83}$. Mindestens teilweise

De iis qui ad Ecclesiam accedunt (CPG 7016), PG 86,33C-37B.

Das ergibt sich aus folgender Beobachtung: Die Abschnitte über die Quartodezimaner und Novatianer bei Timotheos sind inhaltlich völlig parallel und teilweise sogar wörtlich übereinstimmend mit Theodorets Informationen in haer. III 4f. (PG 83,405-408), allerdings etwas knapper. Diese Übereinstimmungen liegen nicht daran, daß Timotheos Theodoret gekannt hat, denn sie finden sich in den Abschnitten zu anderen Häresien nicht in vergleichbarer Weise. Den beiden Berichten liegt also wahrscheinlich eine gemeinsame Quelle zugrunde, etwa ein häresiologisches Handbuch. Allerdings haben beide Autoren "Sondergut", das möglicherweise auf ihren eigenen Informationen über die Novatianer beruht. Im Falle des Timotheos gilt das für die Einfügung der Sabbatianer, bei denen es sich um ein reines Konstantinopolitaner Phänomen handelte (PG 86,37B).

9 Die Erwähnungen bei Germanos von Konstantinopel, Johannes von Damaskos, auf dem Trullanum und in späteren byzantinischen Quellen sind bei Vogt, Coetus (wie Anm. 1), 248 und 288-290 zusammengestellt.

Zum Befund bei Athanasios vgl. Vogt, Coetus (wie Anm. 1), 202-206; zu Theophil vgl. sein kurzes Edictum canonicum: Narratio de iis qui dicuntur cathari (CPG 2678.3).

Photios, bibl. cod. 182 (hg. v. R. Henry, 127a,15-128a,2 Bekker); 208 (165a,1-29 B.); 280 (536a,24-545b,12 B.)

82 Im fünften Buch des Eulogios: Photios, bibl. cod. 182 (127b,2-7 Bekker); 280 (544a,421 B.).

83 Zusätzlich zum schon Besprochenen: Cassiodor, inst. I 5,2 (22,21-23,17 Mynors) kennt einen sehr gebildeten Novatianer „ex partibus Asiae“; die dreizehnte Homilie des 
hatten die Novatianer in diesen Gebieten eine beherrschende Stellung und waren die führende Kirche. In den Großstädten sind novatianische Gemeinden in Konstantinopel, Alexandrien und Rom ${ }^{84}$ belegt, während sie in Antiochien und Syrien zwar möglicherweise vertreten waren, aber kaum große Bedeutung hatten ${ }^{85}$. Die meisten Zeugnisse kommen aus der Hauptstadt des Ostens. Dort stiegen die "Reinen“ bis in die finanziell und politisch höchsten Gesellschaftsschichten auf. Diese Stellung ist nicht zu verstehen allein aufgrund des Rückhaltes im kleinasiatischen Hinterland, selbst wenn sich in der Provinz Novatianer in führenden Stellungen befanden. Vielmehr muß es dort von Anfang an eine bei Hofe einflußreiche und gegenüber der Großkirche selbstbewußt auftretende novatianische Elite gegeben haben. Das schließt selbstverständlich nicht aus, daß die Gemeinde in der Hauptstadt aus den ländlichen Gebieten Kleinasiens Zulauf bekam und sich ihre numerische Stärke von dorther erklärt. Alle diese von Sokrates unabhängigen Informationen bestätigen eindrücklich die Darstellung des Kirchenhistorikers ${ }^{86}$.

Asterios von Amaseia ist scharf gegen die Novatianer gerichtet (v.a. 1,3 [183,13-20 Datema]; Amaseia war die Hauptstadt des Hellenopontos). Die Mitteilung des Philost.

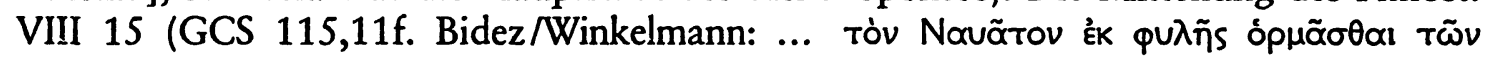
$\Phi$ vermutlich handelt es sich hier um eine (durch Photios oder Philostorgios selbst) mißverstandene Information über den montanistischen Hintergrund des Novatian (die Montanisten wurden auch Phryger genannt).

Sokrates bezeugt Novatianergemeinden in Asien (h.e. VI 11,13, re. Sp.; VI 19,7), Lydien (VI 19,7), Phrygien (IV 28,1.11f. 16f.; V 22,60), Paphlagonien (II 38,29-32; IV 28,1.11f.), Hellespont (II 38,28; III 11,3; V 22,56), Bithynien (IV 28,18; V 21,11; VII 12,7.11; VII 25,16) und Skythien (VII 46,10). Im Rahmen der durch die Zufälligkeit des Materials bedingten Streuung bestätigt er also die Angaben aus anderen Quellen.

84 Für Rom bietet Arnobius iunior (comm. ps. 138,29-75, ferner 70,27; 105,16; 106,2; zur Datierung vgl. H.-D. Daur in der Einleitung zu Arnobius iunior, Commentarii in Psalmos, CChr.SL 25,1, Turnhout 1990, XI: zwischen 432 und 440; Daur [p. XVIf.] vermutet als "Sitz im Leben“ eine aktuelle Kontroverse in Rom) ein interessantes Zeugnis, das die Existenz von Novatianern auch noch Mitte des fünften Jahrhunderts beweist (und damit das Zeugnis des sonst über den Westen schlecht unterrichteten Sokrates [h.e. VII 9.11] stützt). Zu Alexandrien vgl. Sokrates, h.e. VII 7.

Im dritten Jahrhundert hatten die Novatianer auch in Syrien Anhänger gefunden (Vogt, Coetus [wie Anm. 1], 52-55), doch im Laufe des vierten Jahrhunderts werden die Zeugnisse immer spärlicher. Hieronymus, vir. ill. 91,2 (BPat 12, 196,16 Ceresa-Gastaldo) behauptet, Euseb von Emesa habe ein Werk gegen die Novatianer verfaßt; allerdings war Euseb ein weitgereister Mann (vgl. Sokrates, h.e. II 9), so daß nicht leicht zu sagen ist, wo er auf das Thema gestoßen ist (zu den verstreuten antinovatianischen Äußerungen des Euseb in erhaltenen Predigten vgl. Vogt, 201f.). Das nächste Zeugnis stammt von Theodoret von Kyrrhos, der die Novatianer in seinem Haereticarum fabularum compendium behandelt (III 5 [PG 83,405-408]). Wenn allerdings die oben in Anm. 78 vorgetragene These richtig ist, dann kann man darauf nicht allzu viel geben. Daß Theodoret überhaupt selbst mit Novatianern zu tun gehabt hat, ist aus gelegentlichen Erwähnungen in exegetischen Werken zu entnehmen (vgl. Interpretatio in xii epistulas s. Pauli, CPG 6209, PG 82,285B. 453C. 489B. 717C. 773B. 776A. 820BC). Dagegen kommen in seiner Kirchengeschichte die Novatianer überhaupt nicht vor. Auch Sokrates weiß auffälligerweise nichts über Novatianer in Antiochien zu berichten. Auf die Informationen zur Verbreitung wurde schon hingewiesen; die hohe soziale 
IV.

Zur Vervollständigung des Bildes fehlt noch ein Thema, das schon verschiedentlich angeklungen ist und das auf dem Hintergrund des eben Gesagten besser verständlich wird: Die Feier und der Termin des Osterfestes, damit verbunden das von Sokrates breit geschilderte sabbatianische Schisma. In einigen der schon behandelten Texte wurden die Novatianer

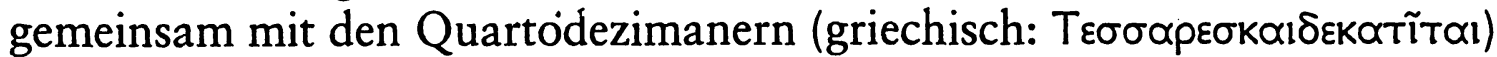
genannt ${ }^{87}$. Wie ist das Verhältnis dieser beiden Gruppierungen zueinander vorzustellen? Kam es zu einer Art Fusion? Handelt es sich von vornherein um identische Gruppen? Oder sind die Gemeinsamkeiten nur eine polemische Unterstellung? Der Schlüssel zu diesen Fragen ist der Termin des Osterfestes. Glücklicherweise haben wir zwei von Sokrates unabhängige Quellen zur novatianischen Osterpraxis. Die eine ist eine weitere pseudochrysostomische Predigt aus dem Jahre 387, die durch ihre Verwendung des asiatischen Kalenders ihre Herkunft aus Kleinasien deutlich zu erkennen gibt ${ }^{88}$. Dort werden drei von der Großkirche abweichende Gruppierungen unterschieden: Erstens die Quartodezimaner (und Juden), die Ostern am 14. Nissan feiern, also eine rein lunare Festlegung ohne Rücksicht auf die Wochentage ${ }^{89}$, zweitens die Novatianer, die das gleiche Datum zugrundelegen, aber Ostern am nächstfolgenden Sonntag feiern ${ }^{90}$,

Stellung der Novatianer bezeugt auch Sokrates, h.e. IV 9,4-6; V 14,8; V 21,2; VI 22,37.20; VII 12,2f.; für die Prägung der Hauptstadtgemeinde ist h.e. V 22,56.60 sehr aufschlußreich (Orientierung am Westen und an der Großkirche!). Vgl. auch A.H.M. Jones, The Later Roman Empire 284-602. A Social, Economic, and Administrative Survey, 3 Bde, Oxford 1964, 956: „The Novatians of Constantinople were evidently more sophisticated than their Phrygian and Paphlagonian brothers." Von der Größe der Gemeinde gibt h.e. II 38,26 eine Vorstellung: Die Novatianer hatten drei Kirchen in der Hauptstadt.

Das ist der Fall in der Epistula de eis qui ad Ecclesiam accedunt (CPG 5983, s. Anm. 71), ebenso im siebenten Kanon von Laodikeia (s. Anm. 30), in den Akten des ephesinischen Konzils (s. Anm. 76) und bei Sokrates, h.e. VI 11,13, re. Sp.; VI 19,7. Wortgleich berichten Theodoret von Kyrrhos und Timotheos von Konstantinopel, also vermutlich auch ihre gemeinsame Vorlage (s. Anm. 78), sogar über die Quartodezimaner:

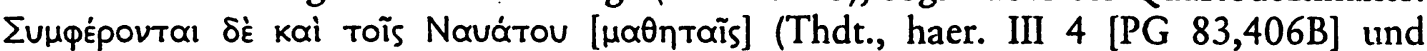
Timotheos, haer. [PG 86/1,36A]).

In sanctum pascha sermo 7 (CPG 4612), zur Herkunft dieser Predigt vgl. die Einleitung von F. Floëri und P. Nautin in: Homélies paschales 3. Une homélie anatolienne sur la date de Paques en l'an 387, SC 48, Paris 1957, 78-83. Der Versuch, innerhalb Kleinasiens Kappadokien als Herkunftsort wahrscheinlich zu machen, ist weniger überzeugend und wohl durch den Wunsch induziert, die Nähe zu Gregor von Nyssa zu erweisen.

$89 \$ 6$ f. (117,1-15 F./N.). Im Unterschied zu Floëri/Nautin (wie Anm. 88), 38 gehe ich nicht davon aus, daß die Quartodezimaner dem Verfasser der Predigt nur noch eine theoretische Realität aus entsprechenden Handbucheintragungen waren. Noch viel später, um die Zeit des Konzils von Ephesos, hat es ja noch eine ganze Menge von ihnen gegeben (s. Anm. 76, auch Sokrates, h.e. VI 11,13, re. Sp.; VIl 29,12)! So mit Recht auch B. Lohse, Das Passafest der Quartadecimaner, BFChTh 2,54, Gütersloh 1953, 122-130.

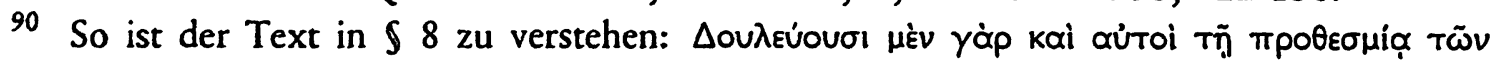

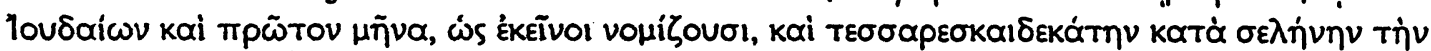

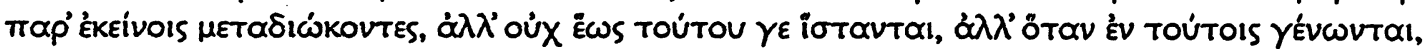


und drittens die Montanisten, die Ostern am ersten Sonntag nach einem festen Kalendertag feiern, und zwar des asiatischen (rein solaren) Kalenders $^{91}$. Hinsichtlich der Novatianer wird dieses Zeugnis vollauf durch Sozomenos unterstützt, der hier sicher von Sokrates unabhängig ist ${ }^{92}$. Demzufolge hätten also die Novatianer eine Art Zwischenlösung zwischen den beiden in Kleinasien üblichen Traditionen der Quartodezimaner und Montanisten praktiziert. Das erstaunt deshalb um so weniger, als sie damit im Trend des größeren Teils der östlichen Kirche in der Mitte des dritten Jahrhunderts lagen, also zu der Zeit, als ihre Sondergemeinschaft entstand $^{93}$. Dagegen legte die von Rom und Alexandrien ausgehende Praxis, die in Nikaia allgemeinverbindlich wurde und sich im Laufe des vierten Jahrhunderts überall durchsetzte, ihr Osterfest nach einem solilunaren System vom jüdischen Festkalender unabhängig fest und befolgte außerdem die Sonntagsregel ${ }^{94}$.

Eine gewisse Schwierigkeit entsteht nun allerdings, wenn man diesen Befund mit dem Zeugnis des Sokrates in Ausgleich zu bringen versucht, insbesondere mit seinem Bericht von der Synode zu Pazos, bei der angeblich die phrygischen Novatianer (und nur sie) beschlossen, als Neuerung (!) sich dem jüdischen, d.h. quartodezimanischen Termin anzuschließen ${ }^{95}$.

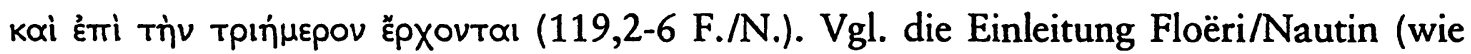
Anm. 88), 39.

91 \9f. (119,9-121,3 F./N.), vgl. dazu A. Strobel, Ursprung und Geschichte des frühchristlichen Osterkalenders, TU 121, Berlin 1977, 197f., ferner Sozomenos, h.e. VII 18,12-15 (dazu Strobel 176ff.). Laut Strobel, 190 Anm. 4 (gegen Huber, Passa [wie Anm. 93], 86f.), spiegelt die Osterhomilie hier schon eine nachnizänische Spätform wider, als der Trend zur Sonntagsfeier auch die Montanisten erreicht hatte.

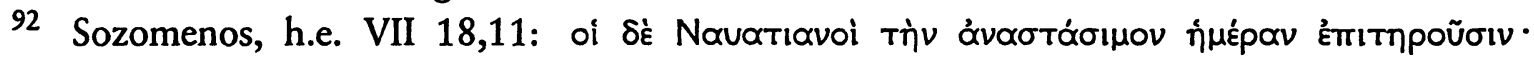

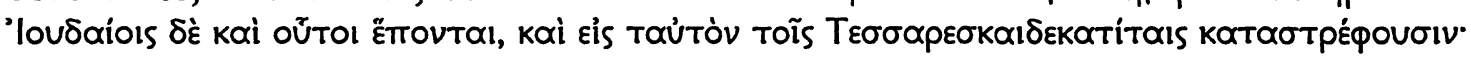

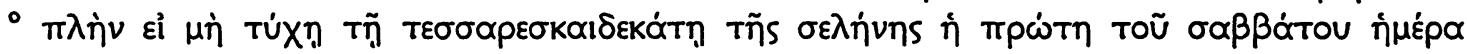

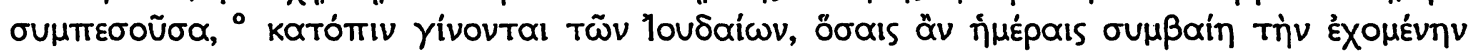

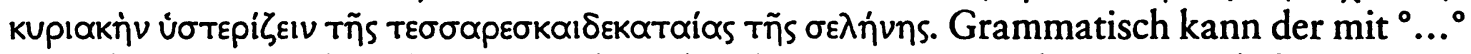
bezeichnete Satzteil auch zum Vorhergehenden gezogen werden (so Strobel, Ursprung [wie Anm. 91], 192), doch wạs soll der Sinn sein? Dann müßte man ja annehmen, daß die Novatianer das Fest verlegen, wenn es mit dem der Juden und Quartodezimaner zusammenfällt (was Sinn ergäbe, denn so war auch die großkirchliche Praxis), und zwar um acht Tage (alles andere wäre Unsinn). Dann wäre aber nicht zu verstehen, warum Sozomenos die Zahl der Tage so umständlich umschreiben sollte. Die von Bidez gewählte Interpunktion begünstigt das richtige Verständnis.

Vgl. Floëri/Nautin (wie Anm. 88), 39f. sowie E. Schwartz, Osterbetrachtungen, ZNW 7, 1906, (1-33) 13-15 und W. Huber, Passa und Ostern. Untersuchungen zur Osterfeier der alten Kirche, BZNW 35, Berlin 1969, 69-75. Diese Observanz hielt sich in der Großkirche bis weit ins vierte Jahrhundert hinein, etwa in Antiochien (vgl. die Predigt In eos qui primo pascha jejunant [Aduersus Iudaeos or. 3, CPG 4327, PG 48,861-872] von Johannes Chrysostomos aus dem Jahre 387) und besonders hartnäckig in Randgruppen wie den Audianern, vgl. Epiphanios, haer. 70,9 (3, 241,14-242,22).

94 Vgl. Schwartz, Osterbetrachtungen (wie Anm. 93), 16-21; Huber, Passa (wie Anm. 93), 64-68; Strobel, Ursprung (wie Anm. 91), 389-392; G. Visonà, Art. Ostern/Osterfest/ Osterpredigt. I. Geschichte, Theologie und Liturgie, TRE 25, Berlin 1995, (517-530) 523.

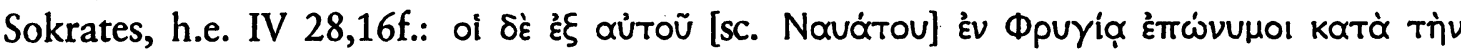

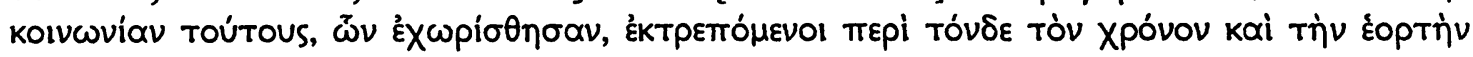


Auch wenn wir den Zeitpunkt dieser Synode nicht genau kennen, hat sie höchstwahrscheinlich stattgefunden, bevor die erwähnte Osterhomilie entstanden ist (387), und ganz sicher, bevor Sozomenos deren Zeugnis bestätigt ${ }^{96}$. Sollten also die Beschlüsse der Synode einfach nicht beachtet worden sein? Eine andere Erklärung scheint mir wahrscheinlicher zu sein. Über die allgemeine Praxis der Novatianer berichtet Sokrates glaubhaft, daß sie sich von Anfang an, an die westliche, d.h. nizänische Regelung hielten (mit der Begründung, daß Novatian an der damals in Rom üblichen Praxis nichts geändert habe ${ }^{97}$. Das wird auch und vor allem auf Konstantinopel zu beziehen sein. In dem Maße, in dem nun im Laufe des vierten Jahrhunderts die gesamte östliche Kirche auf die in Nikaia beschlossene Linie einschwenkte, gerieten die kleinasiatischen Novatianer mit ihrer archaischen Praxis zusehends in die Isolation. Sicherlich wurde auch von ihren Glaubensbrüdern in der Hauptstadt, denen an einem guten Verhältnis zur nizänischen Kirche gelegen war, auf sie Druck ausgeübt, so daß sie schließlich ohne bzw. sogar bewußt gegen die Konstantinopolitaner ${ }^{98}$ an ihrer Tradition festhalten mußten. Es erscheint daher als wenig wahrscheinlich, daß sie als Neuerung auf der Synode von Pazos sich den Quartodezimanern angeschlossen haben (die ja auch zunehmend unter Druck gerieten); sie werden vielmehr die alte kleinasiatisch-novatianische Praxis (Sonntag nach 14. Nissan) festgehalten und sanktioniert haben, was bei polemischer Verfälschung und aus Konstantinopolitaner Perspektive

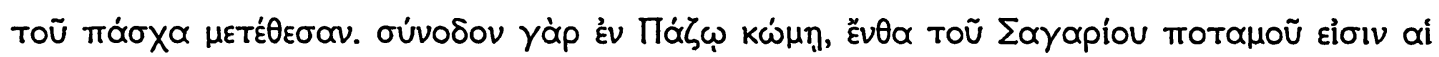

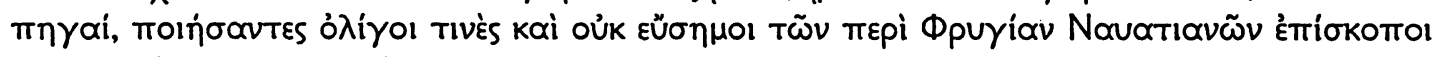

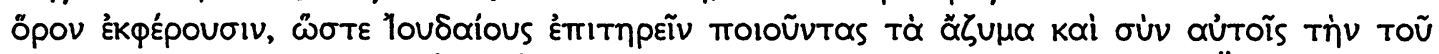

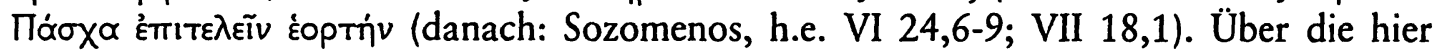
gemachte Angabe des Sokrates hinaus (sowie h.e. V 21,7.13f.) weiß man nichts über den Ort Pazos (oder: Pazon) in Phrygien; insbesondere ist die "genaue Lage unbekannt", L. Zgusta, Kleinasiatische Ortsnamen, BNF. N.F. 21, Heidelberg 1984, \$ 991 (S. 464), vgl. auch Mitchell, Anatolia (wie Anm. 8), 98 Anm. 394. Schon Sozomenos konnte mit der

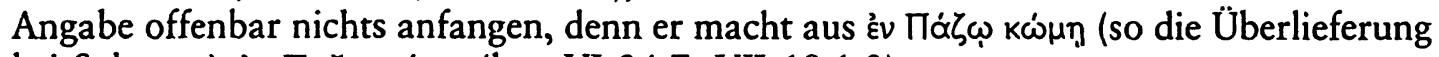

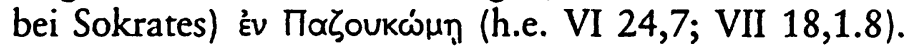

Wenn man der Anordnung der Ereignisse bei Sokrates folgt, müßte die Synode vor der im Anschluß berichteten Bischofswahl des Damasus von Rom (h.e. IV 29) im Jahre 366 (Hieronymus, chron. ann. 366 [GCS Eusebius 7, 244,24f. Helm]) stattgefunden haben. Jedoch wird weit vorher mit Datumsangabe (371) vom Tod des Athanasios (h.e. IV 20,2) berichtet. Auf jeden Fall hat die Synode vor dem Tod des Valens 379 stattgefunden (so auch Sozomenos, h.e. VII 18,1).

H.e. IV 28,14 (vgl. auch V 21,15). Die gleiche Aussage ergibt sich auch aus der Geschichte vom Bischof Akesios auf dem Konzil von Nikaia, der ausdrücklich auf seine Übereinstimmung mit den Konzilsbeschlüssen in dieser Sache hinweist (h.e. I 10,2). Die westliche Ausrichtung speziell der Konstantinopolitaner Gemeinde kommt etwa in h.e. V 22,60 zum Ausdruck.

98 Sokrates, h.e. IV 28,18 betont, daß in Pazos weder der novatianische Bischof von Konstantinopel noch der von Nikaia noch der von Nikomedien noch der von Kotiaeion anwesend war, wo doch angeblich dies die wichtigsten Sitze waren. Bis auf den letztgenannten gehörten sie alle zum Einzugsbereich von Konstantinopel (zur Lage und weiteren Bezeugung von Kotiaeion in Phrygien vgl. Zgusta, Ortsnamen [wie Anm. 95], \$594-3 [S. 294f.], entspricht dem heutigen Kütahya). 
gesehen durchaus zu der Darstellung führen konnte, daß sie sich gegen die kirchliche Praxis und für die jüdische Feier entschieden hätten ${ }^{99}$. Es ist klar, daß bei diesem Stand der Dinge die Spannungen innerhalb der novatianischen Kirche eher ver- als entschärft waren. Genau dies bezeugt Sokrates; es kam zunächst zu dem Versuch einer Unionssynode in Sangaros, bei der die Streitfrage zu einem Adiaphoron erklärt wurde ${ }^{100}$. Doch auch das brachte keine nachhaltige Abhilfe, denn es gab in der Konstantinopolitaner Gemeinde zu viele Kleinasiaten, die auf ihrer Praxis beharrten, so daß innerhalb der Stadt beide Traditionen vertreten waren - ein unhaltbarer Zustand, der schließlich zur Spaltung führte ${ }^{101}$. Damit dürfte der Kern des sabbatianischen Schismas getroffen sein; die von Sokrates breit bezeugten persönlichen Motive bei Sabbatios und die Unterstellung des Judaisierens ${ }^{102}$ müssen deshalb nicht falsch sein, sind aber gewiß als parteiischpolemischer Bericht zu sehen, wie es auch überhaupt von vornherein sehr deutlich ist, daß Sokrates in dieser Frage - ganz gegen seine sonstige Gewohnheit - durchaus nicht sine ira et studio berichtet, sondern eindeutig gegen die Kleinasiaten/Sabbatianer Partei ergreift ${ }^{103}$. Übrigens bestätigt er in diesem Zusammenhang indirekt, daß Sabbatios und seine Leute keineswegs gemeinsam mit den Juden am 14. Nissan ohne Rücksicht auf den Wochentag feierten, sondern die Osternacht sehr wohl von Samstag auf Sonntag begingen; es war dies eben die alte kleinasiatische Praxis der Novatianer ${ }^{104}$, so daß es auch keinen Anlaß gibt zu vermuten, die Synode

Immerhin betont auch der Verfasser der Osterhomilie, der hier keinen besonderen Anlaß zur Polemik hat, die Gemeinsamkeit der Novatianer mit den Juden (s. Anm. 90), obgleich er sich des Unterschiedes wohl bewußt war. Auch Sokrates könnte es eigentlich besser wissen, s. unten bei Anm. 104. Lohse, Passafest (wie Anm. 89), 128f. und Gregory, Novatianism (wie Anm. 1), 13, folgen hier allzu unkritisch Sokrates. Wenn Visonà, Ostern (wie Anm. 94), 523, Nikaia eine anti-jüdische Stoßrichtung unterstellt, so verkennt er den technisch-apologetischen Sprachgebrauch, demzufolge das „Feiern mit den Juden" einfach eine archaische und „abweichlerische" Osterberechnung (etwa der Quartodezimaner) bezeichnet, ohne daß das Judentum als konkretes Gegenüber in den Blick käme. Dieser Sprachgebrauch ist auch bei Sokrates in Rechnung zu stellen.

100 Sokrates, h.e. V 21,11-16 (auch die Namensform "Angaros" ist überliefert, vgl. Hansen [wie Anm. 2], App. zu V 21,11); Sozomenos, h.e. VII 18,3f. Der Ort Sangaros ist in anderen Quellen nicht belegt. Seine genaue Lage ist unbekannt, möglicherweise ist er mit dem heutigen Engüre identisch. Der Name könnte von dem Fluß „Sangarios“ abgeleitet sein (oder auch umgekehrt), vgl. Zgusta, Ortsnamen (wie Anm. 95), \$1157-2 (S. 535), ferner Foss, Autonomus (wie Anm. 7), 191.

101 Sokrates, h.e. V 21,6-19; VII 5; VII 12,5-7.

102 Vogt, Coetus (wie Anm. 1), 247 gewichtet die persönlichen Motive m.E. zu stark. Seine Darstellung S. 245-248 wird insgesamt dem sabbatianischen Schisma nicht ganz gerecht. Der Name Sabbatios ist möglicherweise eher ein Beiname und von "Sabbat" abgeleitet, vgl. Vogt, 245 Anm. 30.

103 Vgl. Wallraff (wie Anm. 5), 80. Bei genauerer Betrachtung zeigt sich auch, daß der ganze Exkurs h.e. V 22 nur auf dieses Problem abzielt, vgl. Wallraff, $248 \mathrm{ff}$.

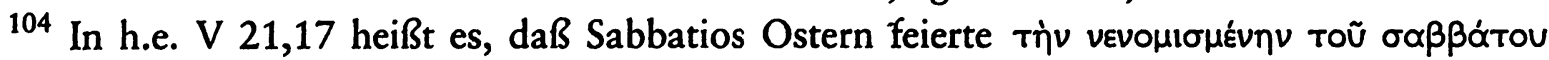

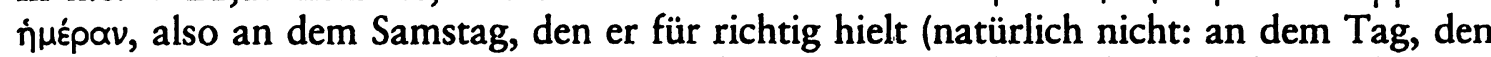
er für den Sabbat hielt), und dann am nächsten Tag mit allen anderen in die Kirche ging 
zu Pazos habe etwas anderes beschlossen ${ }^{105}$. Diese Rekonstruktion der Ereignisse wird durch die anderen Quellen, insbesondere Sozomenos, unterstützt ${ }^{106}$. Von besonderem Interesse ist noch das schon erwähnte Gesetz des Codex Theodosianus, durch das der Gesetzgeber sich in dem innernovatianischen Streit eindeutig gegen die Sabbatianer stellt ${ }^{107}$. So bestätigen auch diese Vorgänge das Bild, demzufolge die Konstantinopolitaner Novatianergemeinde aus zwei Gruppen bestand, nämlich den einflußreichen und etablierten Hauptstädtern und den „kleinen Leuten“ aus dem Hinterland. Gleichzeitig wird verständlich, warum die Novatianer zwar mit Recht als den Quartodezimanern nah verwandt angesehen wurden, aber doch nicht mit ihnen identisch waren.

und die Eucharistie empfing, also am Sonntag (und nicht am 14. Nissan ohne Rücksicht auf den Wochentag wie die Quartodezimaner). Wenig vorher wird auch deutlich, daß die

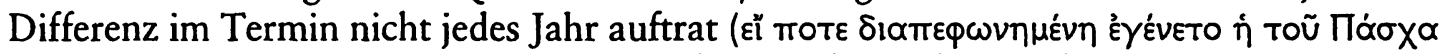
Ėoptí), sondern nur dann, wenn das jüdische Passah vor dem Frühjahrsäquinoktium lag. Die Sonntagsfeier war also nicht strittig. Aus $\$ 18$ ergibt sich, daß Sabbatios’ Praxis genau die der Phryger und Galater war.

105 Sabbatios hat sich ja explizit auf die Synode von Pazos berufen: Sokrates, h.e. V 21,13; Sozomenos, h.e. VII 18,1.

106 In h.e. VII 18,5f. beschreibt Sozomenos die Art des Sabbatios, Ostern zu feiern (nämlich "nach Art der Juden“, aber in der Nacht von Samstag auf Sonntag), und betont, daß er

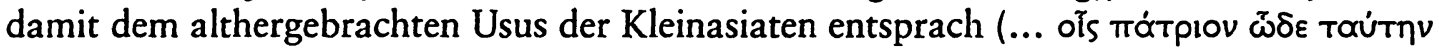

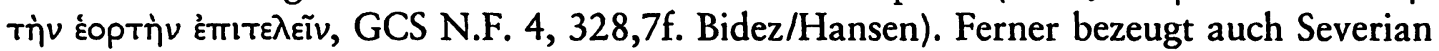
von Gabala, daß es in Konstantinopel schon vor dem offenen Ausbruch des sabbatianischen Schismas Novatianer mit von der Großkirche abweichender Osterobservanz gab: De pascha, deque catharis (CPG 4243, S. 180 und 184 Aucher, s. oben Anm. 60) und dazu Huber, Passa (wie Anm. 93), 82f. Völlig richtig gesehen haben den Hergang Schwartz, Osterbetrachtungen (wie Anm. 93), 15 Anm. 2 (in einer Fußnote) und (ausführlicher) Huber, 79-82; weniger klar dagegen Strobel, Ursprung (wie Anm. 91), 380f. und 175 Anm. 4. - Die übrigen Quellen, in denen die Sabbatianer beiläufig genannt werden, geben keine zusätzliche Information. Die knappe Erwähnung in der Schrift De trinitate I 30,19 (206,1 Hönscheid) kann nicht als ein Zeugnis für Sabbatianer in Ägypten in Anspruch genommen werden (so Vogt, Coetus [wie Anm. 1], 247), denn die herkömmliche Identifikation des Verfassers mit Didymos dem Blinden ist nicht begründet (vgl. J. Hönscheid in: Didymus der Blinde, De trinitate. Buch I, BKP 44, Meisenheim am Glan 1975, 5-7 und B. Kramer, Didymus von Alexandrien, TRE 8, Berlin 1981, [741-746] 743; eher könnte umgekehrt in dieser Stelle ein Indiz für konstantinopolitaner Provenienz der Schrift gesehen werden). Bischof Maruta von Majferqat (um 400) gibt in seinem Ketzerkatalog etwas mehr Information über die Sabbatianer (haer. 1 [ ${ }^{\nu_{5}} \mathrm{f}$., Übers. 76 Rahmani; 7 Harnack], vgl. zu dem Werk I. Ortiz de Urbina, Patrologia syriaca, Rom $\left.{ }^{2} 1965,53\right)$, doch bei näherem Hinsehen erweist er sich als schlecht informiert: Er weiß nichts über ihre Verbindung mit den Novatianern (die er an anderer Stelle anführt, haer. 1 [م f., Übers. 79 Rahmani; 12f. Harnack]) und unterstellt ihnen einfach alle christlichen Klischeevorstellungen vom "Judaisieren". Vermutlich war er über die Situation in Konstantinopel nur oberflächlich unterrichtet - was sich aus seiner Biographie leicht erklären ließe (vgl. J.-M. Sauget, Art. Maruta di Majferqat, DPAC 2, Casale Monferrato 1983, 2157-2159). Aus der beiläufigen Erwähnung bei Prokop, hist. arc. XI 14 (73,1 Haury) ist nicht mehr zu entnehmen, als daß die Gruppe in justinianischer Zeit offenbar noch bekannt war.

107 S. oben bei Anm. 24. 
So rundet sich das Bild von der novatianischen Sondergemeinschaft. Man mag sich allerdings fragen, worin denn in der kirchlichen Praxis der Unterschied zwischen den Novatianern und der Großkirche gelegen haben mag. Offensichtlich wurde von den Gegnern stets die Bußfrage als die entscheidende theologische Differenz angesehen, doch kann man sich kaum vorstellen, daß dieser Frage in der Praxis große Bedeutung zukam. Die endgültige Exkommunikation war bei den Novatianern ja nur für wirklich schwere Sünden vorgesehen, und es gibt kein einziges Zeugnis über einen konkreten Fall im vierten oder fünften Jahrhundert, in dem dies in der von der Theorie geforderten Schärfe praktiziert worden wäre. Verständlich ist die Polemik der Gegner gegen den mit der Bezeichnung $\kappa \propto \theta \propto p o i$ verbundenen Reinheitsanspruch, doch womöglich haben die so Bezeichneten sich selbst aus diesem Grunde im fünften Jahrhundert kaum noch so genannt ${ }^{108}$. Weiterhin ist es bezeichnend, daß auch von den Gegnern nie irgendwelche anderen theologischen Differenzen unterstellt wurden, was indirekt die von Sokrates so nachdrücklich betonte Tatsache bestätigt, daß die Novatianer dogmatisch völlig mit der nizänischen Großkirche übereinstimmten ${ }^{109}$. Sehr wohl allerdings gab es eine Reihe von praktischen Unterschieden, die mehr äußere Gebräuche des kirchlichen Lebens als die Lehre betrafen und sich durchweg dadurch erklären lassen, daß die Novatianer länger als die Großkirche an bestimmten archaischen Gepflogenheiten festgehalten haben. Das gilt sicher, wie gerade gezeigt, für die Frage des Ostertermins, vermutlich auch für die Frage der Wiederverheiratung von Witwen und für den Taufritus. Möglicherweise haben die Novatianer auch die Entwicklung zur Reliquienverehrung nicht mitgemacht ${ }^{110}$. Besonders die hauptstädtische, einflußreiche Gemeinde ist aber in den meisten dieser Fragen alsbald auf den großkirchlichen Kurs eingeschwenkt, so daß die Differenz zu einer nur noch theoretischen wurde (obgleich die getrennten Kirchenorganisationen nach wie vor bestehen blieben).

Über das weitere Geschick der novatianischen Kirche wissen wir sehr wenig. In Konstantinopèl ist sie spätestens im Laufe des siebten Jahrhunderts verschwunden, doch ohne daß ihr Abgang ein lautes Echo in den erhaltenen Quellen hinterlassen hätte. Es hat also wahrscheinlich keine dramatische Verfolgung gegeben, sondern die Gemeinde wird einfach

${ }^{108}$ Die Inschriften haben jedenfalls gezeigt, daß die Bezeichnung Novatianer mindestens ebenso üblich war. Für den Westen bezeugt Rufin, h.e. X 6 (967,9 Mommsen), daß dort die Bezeichnung "die Reinen" ohnehin nicht gebräuchlich war; sie ist auch in den lateinischen Quellen selten und höchstens als Lehnwort aus dem Griechischen belegt.

109 Vgl. etwa h.e. I 10,2; II 38,5; IV 9,1.7; V 10,24.26f.; 14,7; 19,3; VII 11,5f.; Novatianer und Homoousianer werden öfter als ómóppoves bezeichnet.

110 S. Anm. 82. Sollte die in Anm. 7 referierte These von C. Foss allerdings richtig sein, so wäre die Vita Autonomi (BHG 198) ein Beleg für novatianische Verehrung eines Märtyrergrabes. 
immer mehr zerschmolzen sein (nicht umsonst spielt das Thema Konversion in den Quellen eine so große Rolle). Eine entscheidende Rolle wird hierbei ein besonders prominenter Konvertit gespielt haben: Mitte des fünften Jahrhunderts ist der Bischof Markianos, der letzte bei Sokrates erwähnte Hirte der Gemeinde, übergetreten; in der orthodoxen Kirche wurde ihm das Amt des oikonomos der Hagia Sophia angetragen ${ }^{111}$. Eventuell könnte es daraufhin (oder später) sogar zu einem förmlichen Anschluß an die Großkirche gekommen sein, da ja die Annäherungstendenzen ohnehin stark waren.

\begin{abstract}
The Novatianist sect, whose origins in the 3rd century are well known, survived for a surprisingly long time after that; the last traces of the sect in the East are found as late as around 600 . Since the original cause of the schism had vanished with the end of the persecutions, the question as to what the profile and raison d'être of the group were from the 4th century onwards arises. It is this question which the present article addresses, drawing on (I) the few sources of Novatianist origin which have been preserved, (II) legal regulations, both ecclesiastical and secular, and (III) utterances of the Novatianists' orthodox opponents. The picture which emerges indicates significant differences between the communities in Constantinople and its hinterland. While in Asia Minor the sect had preserved its old rigorist and austere profile, the community in the capital.was more mundane and open to Western influences. In particular, it can be shown that at least part of the community was very well established, both economically and politically. The tensions between these two wings eventually lead to schism (the occasion being a controversy over the date of Easter), the consequence of which was a loss of influence, and ultimately the extinction of the community, during the 5th century. While the Novatianists never gained a footing in Syria, the community in Alexandria seems to have survived for a relatively long period, although the evidence is somewhat scanty.
\end{abstract}

${ }^{111}$ Es läßt sich zeigen, daß Markianos, der letzte von Sokrates (h.e. VII 46,9.12f.) erwähnte Novatianerbischof, und Markianos, der oikonomos des orthodoxen Patriarchen Gennadios, der bekanntermaßen ein ehemaliger Novatianer war (Theodoros Anagnostes, h.e. E 376 [GCS N.F. 3, 106,10f. Hansen] und Vita Auxentii, BHG 199, PG 114,1380B), ein und dieselbe Person sind. Die Argumentation im einzelnen trage ich in dem Aufsatz „Markianos - ein prominenter Konvertit vom Novatianismus zur Orthodoxie“ vor (im Druck bei Vigiliae Christianae). 